\title{
Redes de cooperación público-privada y partenariados: retos y pistas para su evaluación. El caso de la Iniciativa Comunitaria Equal en Andalucía
}

\author{
Juan Murciano Rosado \\ Instituto de Estudios de Economía, Evaluación y Empleo, S.L. \\ juanmurciano@ieze.es \\ Laura Porrini \\ Instituto de Estudios de Economía, Evaluación y Empleo, S.L. \\ lauraporrini@ieze.es \\ Carlos Bueno Suárez \\ Instituto de Estudios de Economía, Evaluación y Empleo, S.L. \\ carlosbueno@ieze.es \\ Carmen Vélez Méndez \\ Universidad de Sevilla \\ carmenvelez@us.es
}

Resumen

En las sociedades actuales conviven realidades diversas, con problemas, expectativas y necesidades diferenciadas, cuyo tratamiento escapa a las políticas públicas tradicionales, verticalistas y generalistas. Esto impone la necesidad de pensar nuevos modelos de gestión que permitan optimizar la coordinación de políticas y recursos a escala de los territorios. Así, ha tomado fuerza un modelo de gestión de políticas sustentado en la colaboración institucional, erigiéndose como un nuevo modelo de gobernanza a escala territorial. En este artículo se sintetizan algunos retos y pistas para evaluar partenariados a la luz de las aportaciones teóricas existentes y de nuestra praxis profesional en evaluación, entre las que destaca la evaluación de la experiencia de Equal en Andalucía en materia de redes de cooperación. El análisis se centra en tres elementos: los criterios que deben guiar las evaluaciones, los ámbitos en los que debe centrarse la evaluación y las metodologías de análisis que las sustentan.

Palabras clave Cooperación Institucional; partenariados; evaluación de políticas públicas; gobernabilidad; redes de actores.

\section{Public-private Cooperation Networks and partnerships: Challenges and clues for their evaluation. The case of EQUAL Community Iniciative in Andalucia}

\begin{abstract}
In nowadays societies many realities interact, supposing the coexistence of different problems and needs; which treatment goes further the traditional public policies. This emphasizes the need to think about new management models which could improve the coordination of policies and resources. A management model based on institutional cooperation among key actors is earning its place among public administrators; becoming a new governance model at a local scale. In this article are summarized some challenges and clues to evaluate initiatives based on institutional cooperation; considering the theory available and the professional experience of the authors; like the evaluation of institutional nets created in the framework of the Equal Initiative in Andalucía. Three elements are emphasized: the criteria that traditionally orientate the evaluation processes, the new aspects in which the evaluation has to focus on in order to analyze institutional networks and the methodologies that support this kind of evaluations.
\end{abstract}




\section{OBJETIVOS Y PREMISAS SOBRE LA EVALUACIÓN DE REDES DE COOPERACIÓN}

En este artículo se analizan las redes de cooperación público-privadas bajo la fórmula de partenariados como objeto de evaluación. Para ello, se hace uso de nuestra experiencia en evaluación, aludiendo especialmente a diversos trabajos de seguimiento y evaluación de proyectos en el marco de la Iniciativa Comunitaria Equal en Andalucía 2001-2007 y, destacando entre ellos, la Evaluación de Equal en Andalucía en materia de redes de cooperación institucional (SAE, 2009a).

Se parte de la premisa de que la eficacia e impactos de una intervención articulada bajo la fórmula del partenariado está condicionada, entre otros factores, por la pertinencia de dicho partenariado y la calidad de la participación de cada entidad a lo largo del proceso. En este sentido, se entiende que no es mejor cualquier partenariado que una acción aislada de una entidad y que, por tanto, la evaluación deberá pronunciarse sobre la necesidad y oportunidad del partenariado y sobre su contribución a los logros alcanzados.

Este planteamiento nos ha llevado a construir una propuesta metodológica de evaluación específica y orientada a dar respuesta a las cuestiones relacionadas con el partenariado, realizando una revisión sobre los enfoques, métodos y técnicas que mejor se adaptan a dichos requerimientos.

El enfoque de evaluación que aquí presentamos ha sido aplicado en la citada Evaluación de redes de cooperación en el marco de Equal en Andalucía, una evaluación ex post de impactos. Por ello, los factores clave que se identifican y las propuestas que se realizan se apoyan fundamentalmente en dicha evaluación, que puede considerarse de amplio alcance tanto por el volumen de experiencias de partenariados que aglutina como, sobre todo, porque la Iniciativa Comunitaria Equal constituyó un laboratorio a escala europea para el desarrollo de proyectos experimentales de empleo bajo la fórmula de partenariados y, por tanto, constituye un caldo de cultivo sin parangón para compartir aprendizajes derivados de las evaluaciones que obligatoriamente se realizaron en cada proyecto o aquellas que voluntariamente se impulsaron -como es el caso que aquí se presenta-.

Debe entenderse, pues, como un trabajo que se sitúa en el ámbito de la sistematización de la experiencia evaluativa desarrollada y que se mueve en el terreno de la generación de hipótesis, que debieran ser contrastadas con posteriores evaluaciones de partenariados y comparadas con otras experiencias similares. Así, con este artículo nuestro objetivo es compartir los fundamentos metodológicos del proceso evaluativo desarrollado y sus resultados para, con los primeros, facilitar la contrastación y comparación con evaluaciones de otros casos de partenariados y, con los segundos, difundir los aprendizajes entre responsables públicos y profesionales que desempe-

162 ñan su labor en el ámbito de las políticas públicas. 
El artículo se ha estructurado en tres partes fundamentales. En la primera de ellas se presentan los elementos que justifican el surgimiento de modelos de gestión de las políticas públicas que se apoyan en la cooperación institucional bajo la fórmula de partenariados, especialmente los impulsados desde la Comisión Europea, y que determinan su importancia actual.

En la segunda parte se presentan los requerimientos que se derivan de dichos partenariados en tanto que objeto de evaluación. En este sentido, se realiza un recorrido por el itinerario de la evaluación, destacando en cada fase y etapa las implicaciones concretas que se derivan. Este recorrido se apoya en referencias bibliográficas y en nuestra experiencia en la evaluación de Equal en Andalucía.

En la tercera parte, se presentan recomendaciones de la evaluación objeto de estudio y algunas de las lecciones de la experiencia, orientadas a la detección de los factores clave para la construcción de partenariados eficaces junto a unas consideraciones finales sobre la experiencia.

\section{JUSTIFICACIÓN E IMPORTANCIA ACTUAL DE LAS REDES DE COOPERACIÓN PÚBLICO-PRIVADAS BAJO LA FÓRMULA DE PARTENARIADOS COMO NUEVOS MODELOS DE GESTIÓN DE LAS POLÍTICAS PÚBLICAS}

En las últimas décadas, gran parte de las Administraciones Públicas de países desarrollados o en vías de desarrollo han estado sometidas a importantes procesos de cambio y modernización. En la mayoría de los casos, estos procesos se han visto acelerados, como apunta Osuna, a partir de la coexistencia de dos fuerzas que, desplegadas de manera simultánea, han potenciado el protagonismo de lo local (Osuna, 2006).

Por un lado, se hace referencia a los procesos de integración que en los últimos años han tenido lugar a nivel mundial; lo cual -en mayor o menor medida- ha reducido las cuotas de poder que hasta entonces ostentaba el Estado Nacional, redistribuyendo ciertas prerrogativas en nuevos circuitos administrativos.

Por otro lado, se alude a los procesos de descentralización político-administrativa que han tenido lugar recientemente, que han dado como resultado una multiplicación de entes, organismos y dispositivos territoriales con crecientes competencias, lo que al tiempo que ha supuesto importantes avances en materia de acercamiento de la gestión pública a la ciudadanía, ha conllevado, en algunos casos, una duplicación de servicios y un solapamiento de recursos (Osuna, 2006).

Asimismo, se observa en este panorama una atomización de la sociedad, en donde conviven realidades diversas, con problemas, expectativas y necesidades diferenciadas, cuyo tratamiento escapa a las políticas públicas tradicionales, verticalistas y generalistas. 


\section{CUADRO 1}

Cambio y modernización en las Administraciones Públicas

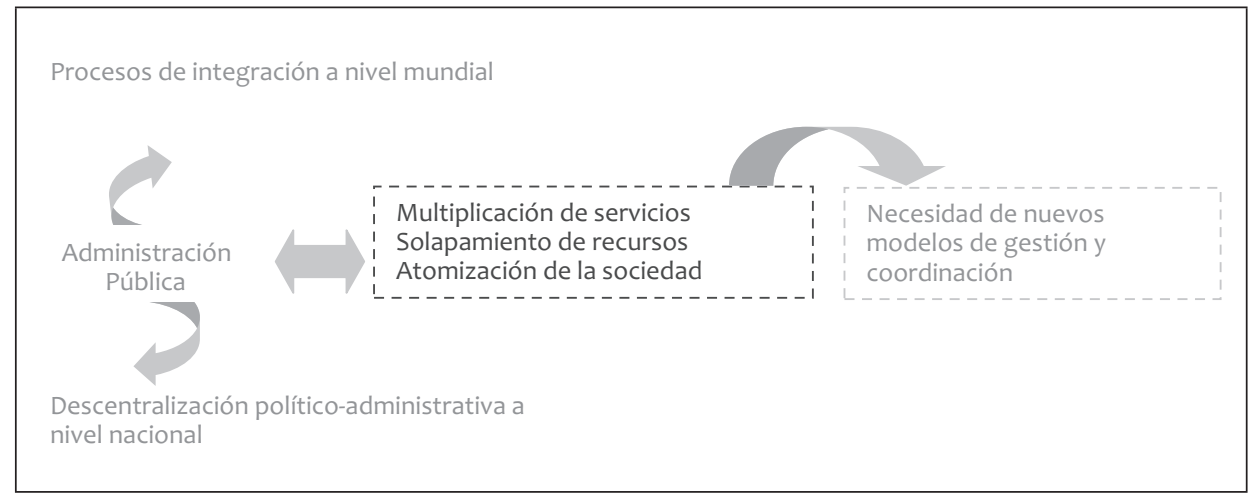

Fuente: Elaboración propia.

En este contexto, la reproducción de modelos de intervención articulados únicamente desde la esfera de la Administración Pública, termina atentando contra la integración misma de la sociedad; agudizando las diferencias entre los que están dentro y los que quedan fuera.

Esta compleja realidad ha impuesto la necesidad de pensar nuevos modelos de gestión que permitan optimizar la coordinación de políticas y recursos a escala de los territorios, colectivos y sectores; generando sinergias que redunden en una potenciación de los procesos de desarrollo a escala local/territorial y en una mayor integración de la sociedad civil. Como afirma Alburquerque: "Esto supone introducir, al nivel más general, una lógica de funcionamiento que desplace enfoques centralistas por un diseño descentralizado de las políticas públicas, las cuales deben dotarse de mayor grado de horizontalidad, selectividad, territorialidad y capacidad de concertación con los actores sociales" (Alburquerque, 2008: 12 módulo 3-).

Lógicamente, la puesta en marcha de nuevos modelos de gestión requiere de una justificación y de una oportunidad que sólo se da en la presencia de factores endógenos y exógenos específicos. Tal como indica Chaqués Bonafont, "el legado histórico y la estructura institucional son una fuente de estabilidad, que limitan las posibilidades de llevar a cabo un cambio radical en la política". Según esta autora, estos periodos de estabilidad son alterados, en ocasiones, por cambios drásticos, que pueden deberse a factores tales como el cambio tecnológico, el envejecimiento de la población, o la universalización del sistema sanitario, entre otros (Chaques, 2009: 72). En este contexto, el modelo de las ventanas de oportunidad política puede explicar los cambios en la política y en los sistemas (Kingdon, 1995).

164 Según este modelo, y sobre la base de la interpretación de Chaqués Bonafont, "el 
cambio en una política pública es el resultado de una compleja interacción entre tres procesos distintos que en principio siguen cursos diferentes y no están relacionados entre sí -el proceso relativo a los problemas, el proceso relativo a cambios en el sistema político, y el proceso relativo a las ideas disponibles-" (Chaques, 2009: 73). Los cambios en estos tres procesos y su interacción crean, en algunas circunstancias, la ventana de oportunidad necesaria para que el cambio en la política pública ocurra.

Este modelo explica, en parte, el paso de los modelos de gestión individual de las políticas públicas a los sustentados en la gestión asociada. En este caso, la ventana de oportunidad se abre a partir de la coexistencia de diversos factores -como la convivencia de una pluralidad de grupos étnicos en un mismo territorio o las nuevas dinámicas de inclusión/exclusión que impone la globalización- que producen un cambio radical en los problemas que afectan a las comunidades, que exigen soluciones gestadas desde la multidimensionalidad, a lo que se suma -entre otras cuestiones- los cambios en el sistema político-administrativo, producto de los procesos de integración que tienen lugar a nivel mundial y de la descentralización acaecida en el interior de las fronteras nacionales.

Así, como una respuesta natural a estos procesos, emerge el modelo de gestión de las políticas locales sustentado en la colaboración institucional entre los actores clave de cada territorio; erigiéndose como un nuevo modelo de gobernanza a escala territorial.

En este sentido, tal como se expresa en el Libro Blanco de la Gobernanza Europea, "la reforma de la gobernanza aborda la cuestión de cómo... (la administración)... utiliza los poderes que le otorgan sus ciudadanos. Se refiere a la manera en que las cosas podrían y deberían hacerse. El objetivo es abrir el proceso de decisión política para dotarlo de unos mayores niveles de integración y responsabilidad. Un mejor uso de sus poderes debería permitir una conexión más directa con los ciudadanos y dar lugar a unas políticas más efectivas... Esto significa que el modelo lineal consistente en decidir las políticas desde arriba debe ser sustituido por un círculo virtuoso basado en la interacción, en las redes existentes y en una participación a todos los niveles, desde la definición de las políticas hasta su aplicación" (Comisión de las Comunidades Europeas, 2001: 8-12) -pasando por su evaluación compartida-.

Esta nueva gobernanza basada en la colaboración institucional supone, entre otras cosas, horizontalizar la gestión de las políticas a escala local, implicando y coresponsabilizando a nuevos actores en su diseño, ejecución y evaluación, lo que a su vez impactaría en una mayor complementariedad de recursos y en una maximización de las oportunidades de desarrollo del territorio, colectivo o sector. Asimismo, la inclusión de instituciones de diversa procedencia y objetivos en el ciclo de vida de las políticas públicas permitiría ampliar las bases de la democracia representativa; posibilitando el diseño e implementación de políticas mucho más adaptadas a las necesida- 
des de los distintos grupos de ciudadanos y ciudadanas y que atienda, a su vez, a la diversidad dentro de cada grupo.

La colaboración institucional en la gestión de las políticas implica un modelo de trabajo basado en la cooperación entre instituciones de distinta naturaleza que, en la medida de sus posibilidades, capacidades e intereses, acuerdan colaborar en el desarrollo de un proyecto conjunto; movilizando los recursos disponibles al servicio de la búsqueda de nuevas soluciones a las problemáticas de las comunidades actuales (SAE, 2007: 6).

La puesta en marcha de un modelo de gestión basado en la colaboración institucional requiere, por tanto, la cooperación de entidades en el ámbito de un partenariado con el fin de dar un tratamiento integrado a las distintas problemáticas que motivan la cooperación. Así, en los últimos años, desde ámbitos diferenciados -muy directamente desde la Comisión Europea- se ha promovido la constitución de estos partenariados, integrados por agentes público-privados, como pilar a partir del cual gestionar políticas públicas en diversas materias (políticas de empleo, desarrollo rural y regional, o cooperación internacional, entre otras).

Esta apuesta de la Comisión Europea por el partenariado como eje vertebrador y vía de apropiación de políticas de desarrollo territorial y local encuentra su germen en el programa experimental de Pactos Territoriales por el Empleo impulsado a finales de la década de los noventa y, posteriormente, se erigen como corolarios y ejemplos paradigmáticos las Iniciativas Comunitarias desarrolladas en el periodo de programación 2001-2007, entre ellas Leader + y Equal, en las que la construcción de dicho partenariado constituye una prerrogativa.

Este nuevo modelo de gestión de las políticas públicas nos sitúa ante una concepción del desarrollo socioeconómico entendido como un proceso integral y participativo de un territorio con identidad propia, en el que las condiciones de vida de la sociedad local mejoran de manera sostenida tanto en lo económico, social, cultural, institucional y político de manera que se logre el bienestar generalizado de la población (OIT, 2008).

A pesar de las ventajas que conlleva, la puesta en marcha de un modelo de gestión de estas características no constituye una tarea fácil; no sólo desde un punto de vista práctico -en tanto está condicionado por la voluntariedad de la participación de los actores locales-, sino también desde un punto de vista teórico-axiológico, pues supone que cada uno de estos actores esté dispuesto a ceder protagonismo a favor del todo, aminorando las asimetrías de poder y favoreciendo la construcción y el desarrollo de capacidades.

Estas dificultades, junto a las visibles ventajas que acarrea la aplicación de estos modelos de gestión en partenariados requieren el desarrollo de metodologías de 166 evaluación que posibiliten maximizar su potencial, contribuyendo de esta forma a la 
generación de políticas públicas adaptadas a las necesidades actuales de cada contexto de intervención.

\section{LA EVALUACIÓN DE LOS PARTENARIADOS: APROXIMACIONES Y PROPUESTAS}

Justificada la importancia actual de los partenariados, su consideración como objeto de evaluación es la que resulta especialmente relevante a los efectos de este artículo. La coparticipación de entidades en un partenariado genera un contexto en el que la propia participación y gestión emergen como factores clave del éxito y, en consecuencia, en determinantes del mérito o valor de las intervenciones sobre las que la evaluación debe emitir un juicio crítico y sistemático (Murciano, 2006).

Por tanto, la evaluación de las intervenciones que se desarrollan bajo la fórmula de partenariado debe orientarse no sólo al enjuiciamiento de su eficacia, sino también al examen del propio partenariado como estrategia de desarrollo, en tanto que puede actuar como catalizador de dicho proceso en la medida que lo facilita o inhibe.

En esta misma línea de pensamiento, y siguiendo al profesor Joan Subirats, "si aceptamos que el trabajo compartido, el trabajo en red, es hoy determinante en las políticas de inclusión, debemos reconocer que la búsqueda de estrategias para tener en cuenta el valor generado por la construcción de esa red, y la evaluación de su eficacia, su capacidad de aprendizaje conjunto y su fuerza para el futuro, son elementos cada vez más significativos en toda dinámica de evaluación de las políticas sociales actuales" (Subirats, 2005: 35-36).

Y en esta búsqueda de estrategias de evaluación que permitan enjuiciar estas redes de gestión, hay que tener en cuenta el carácter netamente empírico del concepto de partenariado, que evoluciona progresivamente con los actores que lo construyen y perciben, y la necesidad de examinar su idoneidad según cada contexto (Handicap Internacional, 2002).

Este carácter empírico y contextual del partenariado es el que configura a su evaluación como una oportunidad para "avanzar en la discusión de hipótesis más concretas relativas al papel de los contextos estructurales sobre los procesos de decisión, tanto los que se refieren a las percepciones y las reglas informales sobre el poder, como los que identifican los canales y formas de relación entre actores y su articulación dentro de las redes que forman" (Jordana, 2009: 11).

Ahora bien, a pesar de la relevancia que posee hoy día la evaluación de los partenariados, no existe una propuesta evaluativa unánime, ni siquiera existen muchas referencias en la literatura especializada; por lo que se erige como uno de los retos actuales de la evaluación de políticas públicas (Osuna et al., 2006). 
Entre las referencias que pueden guiar este análisis encontramos desde la psicología, el estudio de las coaliciones comunitarias (Martínez y Martínez, 2003), y desde otras disciplinas, los estudios y aproximaciones a la medición del capital social (Román, 2001; Román y Rodríguez, 2006), o el análisis de redes (Garrido, 2003) -objeto de un reciente monográfico de la Revista GAPP-.

\subsection{Pistas para evaluar partenariados a partir del caso de Equal en Andalucía}

En los siguientes apartados se sintetizan retos y pistas para evaluar partenariados a la luz de las aportaciones teóricas existentes y de nuestra praxis profesional en evaluación. Tras presentar unos datos básicos sobre el modelo de gestión aplicado con Equal en Andalucía se toma como base la Evaluación de la experiencia Equal en Andalucía en materia de Redes de cooperación institucional (SAE, 2009a) para, a partir de ella, sistematizar las implicaciones que tiene que evaluar un partenariado y sus principales ámbitos de incidencia a lo largo de las principales etapas que se recorren en el itinerario de cualquier evaluación. En cada una de estas etapas, presentadas en los cuatro apartados siguientes, se muestran las opciones de método y técnicas seleccionados en dicha evaluación, justificándolos tanto en el propio contexto evaluativo como en la literatura existente en materia de evaluación de políticas públicas y, en la medida de lo posible, añadiendo extractos ejemplificadotes de los hallazgos del proceso evaluativo.

\section{CUADRO 2}

El caso de la Iniciativa Comunitaria Equal: la acción del partenarido como mecanismo de gestión

La Iniciativa Comunitaria Equal, diseñada con el fin de promover nuevas maneras de combatir todas las formas de discriminación y desigualdad en relación con el mercado de trabajo, propuso el partenariado como plataforma desde donde gestar y gestionar soluciones innovadoras en materia de empleo e inclusión. El modelo de gestión de las políticas de empleo sustentado en la colaboración institucional entre actores clave emergió como una respuesta a las necesidades de coordinación y complementariedad que demandaba la realidad local ante la multiplicidad de instituciones, entidades y dispositivos que ha ido generando el proceso descentralización y la configuración de una administración multinivel.

Concretamente, Equal proponía la conformación de partenariados-denominados en el marco de Equal agrupaciones de desarrollo (AD)- como pilar sobre el que construir proyectos experimentales de empleo en 6 áreas temáticas diferenciadas; otorgándoles a dichas AD la gestión del ciclo de vida de cada proyecto, desde su conceptualización y diseño hasta su evaluación. La agrupación de desarrollo consistía en un acuerdo establecido por los agentes clave de un territorio o sector con voluntad de cooperar en el desarrollo (o la búsqueda) de soluciones a los problemas de desigualdad en el mercado laboral. 


\author{
CUADRO 2 (cont.) \\ El caso de la Iniciativa Comunitaria Equal: \\ la acción del partenarido como mecanismo de gestión
}

En el marco de Equal en Andalucía se ejecutaron, en el periodo 2001-2007, 70 proyectos cuya gestión estuvo a cargo de 47 agrupaciones de desarrollo que contaron con la participación de 394 entidades, gran parte de ellas representadas por la Consejería de Empleo de la Junta de Andalucía. Si se excluyen aquellas que participaron en más de una AD, esta cifra se reduce a 286 entidades participantes; con una media de 9 entidades por partenariado. El $30 \%$ de entidades participantes fue representativa de algún colectivo o sector prioritario; y de ellas, el 40\% fueron entidades de mujeres, el $21 \%$ asociaciones de desarrollo local, el $15 \%$ de personas con discapacidad y el resto representaron a personas inmigrantes, minorías étnicas y jóvenes, entre otros.

Fuente: Extracto del resumen ejecutivo de la evaluación de la cooperación institucional experimentada con Equal en Andalucía (SAE, 2009a: 5).

Sobre la base de la experiencia adquirida en el marco de la evaluación de la experiencia de Equal en Andalucía en materia de redes de cooperación', entre los desafíos que impone la valoración de la red y la evaluación de su eficacia, al menos cuatro elementos deben ser considerados:

1. La oportunidad del propio partenariado como estrategia de desarrollo ad hoc;

2. La necesidad de redefinir el concepto y el alcance de los criterios que tradicionalmente han guiado a los procesos evaluadores;

3. La conveniencia de repensar los ámbitos en los que debe centrarse la evaluación, y

4. La importancia de identificar metodologías de análisis adecuadas, capaces de responder a los requerimientos de información implícitos en evaluaciones de estas características.

En la siguiente tabla se presentan estos elementos que deben tenerse en cuenta en una evaluación de procesos de gestión basados en la colaboración institucional, considerados como parte de las etapas que, en mayor o menor medida, marcan el itinerario de toda evaluación; y que serán abordados en profundidad en los epígrafes siguientes:

1 Para más información sobre la Iniciativa comunitaria Equal en Andalucía puede consultarse www.juntadeandalucia.es/empleo/equal 


\section{CUADRO 3}

Cuatro etapas en la evaluación de los partenariados

\begin{tabular}{|c|c|}
\hline Etapa & Ámbitos de análisis \\
\hline $\begin{array}{l}\text { 1. Valoración de la necesidad/oportunidad } \\
\text { de la puesta en marcha de procesos de } \\
\text { gestión basados en la colaboración insti- } \\
\text { tucional. }\end{array}$ & $\begin{array}{l}\text { - Carácter de las problemáticas } \\
\text { - Complejidad de las soluciones } \\
\text { - Disponibilidad de recursos } \\
\text { - Importancia de la financiación } \\
\text { - Diversidad de destinatarios/as } \\
\text { - Tipología de entidades }\end{array}$ \\
\hline $\begin{array}{l}\text { 2. Particularización de cuestiones de eva- } \\
\text { luación y criterios }\end{array}$ & $\begin{array}{l}\text { - Pertinencia } \\
\text { - Eficacia } \\
\text { - Eficiencia } \\
\text { - Impacto } \\
\text { - Viabilidad }\end{array}$ \\
\hline $\begin{array}{l}\text { 3. Identificación de nuevos ámbitos de eva- } \\
\text { luación }\end{array}$ & $\begin{array}{l}\text { - La estructura organizativa de la red y } \\
\text { las modalidades de coordinación ar- } \\
\text { ticuladas }\end{array}$ \\
\hline $\begin{array}{l}\text { 4. Identificación de metodologías de análi- } \\
\text { sis adecuadas }\end{array}$ & $\begin{array}{l}\text { - Teoría del programa } \\
\text { - Análisis de redes sociales } \\
\text { - Análisis y medición del capital social }\end{array}$ \\
\hline
\end{tabular}

Fuente: Elaboración propia.

En todos los casos, la evaluación de modelos de gestión basados en la colaboración institucional impone la necesidad de ampliar el objeto de evaluación, complementando la evaluación centrada en resultados con una valoración de los mecanismos de gestión implementados; aspecto que deberá considerarse de manera transversal y a lo largo de todo el proceso evaluador.

Esta doble consideración de los resultados alcanzados por la intervención (y las relaciones causa-efecto que tienen lugar en el proceso) y de los mecanismos puestos en marcha en su implementación es lo que Huey-Tysh Chen llama "evaluación iluminadora"; en tanto que arroja luz a los socios del partenariado sobre los supuestos clave sobre los que se supone que el partenariado opera y sobre los distintos componentes del programa que contribuyen a su éxito o fracaso (Chen, 2005).

Así, no se trata de reemplazar las metodologías de evaluación tradicionales, sino más bien de ampliar su foco de análisis y desarrollar la necesaria contextualización y particularización de las cuestiones a resolver y de las opciones que ofrece la evalua170 ción de políticas públicas para el caso de los partenariados. 


\subsection{Evaluación de la oportunidad del partenariado}

Los partenariados público-privados se sustentan en acuerdos establecidos por los agentes clave de un territorio o sector con voluntad de cooperar en el desarrollo (o la búsqueda) de soluciones a los problemas que afectan a las comunidades, incluyendo en la gestión de las políticas públicas a un vasto espectro de actores representativos de las distintas realidades que conviven en las sociedades actuales.

La oportunidad de un partenariado de esta naturaleza hace referencia a la idoneidad de su composición en relación con las necesidades que lo motivan. Hay que tener en cuenta que las experiencias de gestión basadas en la cooperación no tienen por qué suponer beneficios en todos los casos; requiriéndose, como primera etapa en el proceso evaluador, la valoración de la necesidad y viabilidad de la puesta en marcha de modelos de gestión de estas características.

Y en esta valoración será preciso considerar algunos aspectos clave, recogidos en el cuadro siguiente, como el carácter de las necesidades y problemas que justifican la constitución del partenariado; la complejidad de las soluciones que exige la realidad; la disponibilidad de recursos necesarios para hacer frente a la intervención -técnicos, humanos y, especialmente, financieros-, y la homogeneidad/heterogeneidad que caracteriza a los colectivos destinatarios de las intervenciones, en tanto que una mayor diversidad conlleva la necesidad de articular mecanismos de trabajo basados en la interdisciplinariedad. En relación con la disponibilidad de recursos financieros, Savas expresa que los partenariados son aconsejables cuando existe una clara necesidad de desarrollar un proyecto concreto, no existe suficiente presupuesto público para desarrollarlo, y existen beneficios potenciales derivados de la obtención de nuevas fuentes de financiación, de una implementación más ágil, de un diseño innovador y de una operativa eficiente (Savas, 2000).

Concretamente, la multidimensionalidad que en la actualidad caracteriza a las problemáticas y a las políticas es el factor que marca el paso de un modelo de gestión individual o con una participación restringida, en donde la dinámica es vertical y los problemas y soluciones se conciben de una manera generalista y con cierto grado de homogeneidad; a otro modelo de gestión colectiva (multiplicidad de agentes), sustentado en una dinámica horizontal o reticular a través de la cual se pretenden ofrecer respuestas selectivas y adaptadas a problemáticas particulares (SAE, 2009b).

Una vez determinada la necesidad del partenariado, su oportunidad viene condicionada por la idoneidad de las instituciones que lo conforman en relación con las necesidades especificas de los colectivos, territorios y sectores objeto de la intervención. Es por ello que la representatividad y el grado de participación de entidades especializadas en la intervención en dichos territorios, sectores y colec- 
tivos se configuran como indicadores clave para enjuiciar la conveniencia de la acción del partenariado como estrategia de gestión, si bien estas cuestiones podrían englobarse en el marco del criterio de pertinencia al que se hace referencia más adelante.

\section{CUADRO 4}

La necesidad del partenariado: factores que determinan su constitución

\begin{tabular}{|c|c|}
\hline Modelo de gestión tradicional \\
(individual)
\end{tabular}

Fuente: Elaboración propia.

Así, considerando a la tipología de entidades socias de manera aislada, aparecen como ámbitos de análisis relevantes los siguientes:

- Los roles asumidos por cada entidad socia, siendo importante estudiar el grado de aprovechamiento de las "ventajas competitivas" de cada una, lo cual puede impactar en la eficacia y en la eficiencia del proyecto implementado.

- La aparición de agentes “no tradicionales” en la gestión de las políticas públicas, destacando la necesidad de centrar el análisis en la representatividad de estos actores y en la posibilidad que su participación significa en cuanto a la inclusión -en la gestión de las políticas públicas- de subgrupos específicos de la sociedad.

- El grado de participación de los distintos sectores representativos de la sociedad. Esta línea de análisis, directamente relacionada con el punto ante- 
rior, se refiere también a la necesidad de evaluar el grado de participación de los agentes locales en el partenariado en función de los requerimientos de cada situación específica. Es decir, se trata de definir, en el marco del proyecto concreto que gestiona el partenariado, qué agentes deberían estar presentes si lo que se pretende es garantizar el cumplimiento de los objetivos planteados.

\section{CUADRO 5}

\section{Ámbitos de evaluación relacionados con la tipología de entidades}

\begin{tabular}{|c|c|}
\hline Rol asumido desde cada entidad & $\begin{array}{l}\text { Aprovechamiento de las ventajas } \\
\text { competitivas de cada socio }\end{array}$ \\
\hline \multicolumn{2}{|c|}{ Inclusión de actores no tradicionales en la gestión de las políticas públicas } \\
\hline $\begin{array}{l}\text { Representatividad de los actores que } \\
\text { conforman el partenariado }\end{array}$ & $\begin{array}{l}\text { Responsabilidades compartidas } \\
\text { (horizontales) }\end{array}$ \\
\hline Inclusión de subgrupos específicos. & $\begin{array}{l}\text { Acercamiento (nexo directo) entre los } \\
\text { objetivos de los proyectos y sus } \\
\text { destinatarios/as }\end{array}$ \\
\hline
\end{tabular}

Grado de participación de los distintos actores locales

Implicación/liderazgo de las

Administraciones públicas

Relación entre las entidades socias, los objetivos del proyecto y los colectivos beneficiarios de las actuaciones
Incentivo a la participación de actores clave Legitimación/validación de la acción del partenariado

Adecuación de las políticas a sus verdaderos destinatarios/as Focalización de recursos en demandas/ necesidades concretas Mayor aprovechamiento de las oportunidades que ofrece el territorio

Fuente: Elaboración propia.

Estas cuestiones, además de constituir referentes para la evaluación de la red, contribuyen a generar responsabilidades de forma horizontal y pueden presentar un alto grado de incidencia en la capacidad de impacto, viabilidad, pertinencia, eficiencia y eficacia de las políticas y proyectos articulados; en tanto que suponen un nexo directo entre los objetivos y las personas destinatarias, posibilitando el diseño de actuaciones más concretas y selectivas, centradas en necesidades específicas y gestionadas por agentes plenamente involucrados en las problemáticas de los subgrupos que representan. Si bien, el análisis de algunas iniciativas gestionadas 
desde la acción del partenariado² ha puesto de manifiesto que para que esto suceda se requiere:

- La implicación activa -y en muchos casos el liderazgo- de las diversas instituciones representativas de la Administración Pública con poder de decisión y manejo de recursos, en tanto que su presencia puede incentivar la participación de otros actores clave, legitimando y validando la acción del partenariado. Asimismo, es preciso tener en cuenta dos cuestiones complementarias: por un lado, que el desarrollo de proyectos paralelos a aquellos liderados desde la Administración Pública puede contribuir a la reproducción de prácticas simultáneas más que a la potenciación de recursos escasos; y, por otro, que las posibilidades de sostenibilidad de las iniciativas de cooperación se reducen considerablemente si no se cuenta con el apoyo y liderazgo del actor protagonista y competente en materia de políticas públicas.

- La relación, dentro del partenariado, entre las entidades socias, los objetivos del proyecto y los colectivos beneficiarios de las actuaciones; lo cual puede incidir en una mayor adecuación de las políticas a sus verdaderos destinatarios/as, en una focalización de los recursos en demandas/necesidades concretas y en un mayor aprovechamiento de las oportunidades que ofrece el territorio.

Y en este aspecto es interesante prestar atención a lo que Calame denomina una condición previa a la instauración de verdaderas relaciones de partenariado, haciendo referencia a las posibilidades reales de participación de cada actor, que deben ser evaluados antes de la conformación de la red. En este sentido, puntualiza que no todos los actores tienen la misma posibilidad concreta de instituirse y de construir un discurso legítimo, ni la capacidad de influencia en la toma de decisiones, ni los recursos financieros que, en ocasiones, la participación requiere (Calame, 2006).

Finalmente, resulta importante resaltar que la participación no debe confundirse con la cantidad, pues las experiencias analizadas demuestran que un número elevado de entidades socias puede incidir, en ocasiones, de forma negativa sobre la operatividad del modelo de gestión por el incremento en los costes de transacción que los procesos de negociación conllevan.

Tomando como referencia las conclusiones de la evaluación del modelo de cooperación institucional articulado en el marco de la Iniciativa Comunitaria Equal

2 Cuando se menciona el análisis de algunas iniciativas gestionadas desde la acción del partenariado hacemos referencia a diversos trabajos de evaluación de los autores, sobre todo un conjunto de 174 Andalucía, citados en la bibliografía. 
en Andalucía “la composición amplia y heterogénea de los partenariados, incorporando y corresponsabilizando a nuevos actores en torno a un objetivo común y sobre la base de su representatividad, capacidad y experiencia, ha dotado a las intervenciones de mayores dosis de pertinencia y coherencia" (SAE, 2009b: 6). De esta manera, el análisis de la composición de los partenariados ha permitido observar algunos aspectos singulares de las agrupaciones de desarrollo (AD), ante los cuales cada una de ellas ha registrado un posicionamiento particular entre un amplio abanico de alternativas, cuyos extremos se muestran en la siguiente tabla.

\section{CUADRO 6}

Análisis de la composición de los partenariados Equal en Andalucía: resumen de los principales hallazgos

\begin{tabular}{|c|c|c|}
\hline Extremo 1 & Aspecto & Extremo 2 \\
\hline Mínimo (3) & Número de socios & Máximo (19) \\
\hline $\begin{array}{l}\text { Escasa relación entre } \\
\text { entidades y colectivos } \\
\text { destinatarios }\end{array}$ & $\begin{array}{l}\text { Representatividad de los } \\
\text { colectivos diana }\end{array}$ & $\begin{array}{r}\text { Representatividad a nivel de } \\
\text { subgrupos específicos }\end{array}$ \\
\hline $\begin{array}{l}\text { Baja presencia de entidades } \\
\text { del territorio }\end{array}$ & $\begin{array}{l}\text { Conocimiento del ámbito de } \\
\text { intervención }\end{array}$ & $\begin{array}{l}\text { Fuerte participación del } \\
\text { tejido institucional local }\end{array}$ \\
\hline $\begin{array}{l}\text { Escasa relación entre las } \\
\text { entidades y las } \\
\text { problemáticas a solucionar } \\
\text { por el proyecto }\end{array}$ & $\begin{array}{c}\text { Experiencia en las } \\
\text { problemáticas que } \\
\text { sustentan las acciones del } \\
\text { proyecto }\end{array}$ & $\begin{array}{r}\text { Presencia de entidades } \\
\text { especializadas en las } \\
\text { problemáticas que dan } \\
\text { forma al proyecto }\end{array}$ \\
\hline $\begin{array}{l}\text { Participación de algunos } \\
\text { actores locales de referencia } \\
\text { en materia de empleo }\end{array}$ & $\begin{array}{l}\text { Presencia de actores locales } \\
\text { clave en materia de empleo }\end{array}$ & $\begin{array}{r}\text { Convocatoria a todos los } \\
\text { actores locales clave en } \\
\text { materia de empleo }\end{array}$ \\
\hline $\begin{array}{l}\text { Compromiso de los equipos } \\
\text { técnicos }\end{array}$ & $\begin{array}{l}\text { Generación de compromisos } \\
\text { en la AD y en las propias } \\
\text { entidades con el modelo de } \\
\text { cooperación }\end{array}$ & $\begin{array}{r}\text { Compromisos de } \\
\text { cooperación de las } \\
\text { entidades a todos los } \\
\text { niveles, tanto técnico como } \\
\text { político }\end{array}$ \\
\hline
\end{tabular}

Fuente: Elaboración propia a partir de SAE (2009b: 149).

\subsection{Particularización de cuestiones de evaluación y criterios}

Si la evaluación tiene como cometido ofrecer respuestas a cuestiones de interés sobre las políticas públicas, que presentan un alto grado de incertidumbre y relevancia para los actores implicados en ellas, es la explicitación de dichas cues- 
tiones la que marca el inicio del diseño de toda evaluación. Estas cuestiones suelen estar asociadas a los criterios de valor que facilitan la labor de enjuiciamiento evaluativo. Independientemente de la existencia y utilidad de criterios complementarios según cada contexto, y prescindiendo en un primer momento de su dialéctica con evaluaciones más comprensivas, un recorrido por la literatura actual en materia de evaluación permite observar un consenso sobre la existencia de cinco criterios básicos³: pertinencia, eficiencia, eficacia, impactos y viabilidad (MAEC, 2007).

Son estos criterios principales los que, a continuación se analizan para el caso de los partenariados.

- En el marco de un modelo de gestión basado en la colaboración institucional, la evaluación de la pertinencia deberá atender, también, a la adecuación de las entidades socias que conforman el partenariado a las especificidades de la población beneficiaria y al contexto de intervención; suponiendo la consideración de aspectos tales como el grado de participación del tejido institucional local o el nivel de representatividad de los socios del partenariado respecto a la población destinataria, entre otras cuestiones de importancia.

- Si lo que se evalúan son proyectos y acciones gestionados desde la cooperación institucional, para la evaluación de la eficiencia será preciso considerar aspectos tales como la puesta en marcha de mecanismos destinados a promover la coordinación de los recursos de los socios del partenariado, en tanto que una superposición de recursos a nivel de partenariado restaría eficiencia a las acciones emprendidas.

- Para la evaluación de la eficacia se torna clave definir en función de qué parámetros se considera que un modelo de cooperación ha sido eficaz; siendo necesario considerar aspectos tales como: la operatividad del modelo de gestión implementado; la sostenibilidad de la acción del partenariado y la propia capacidad del modelo para alcanzar los objetivos planteados.

- Tomando como referencia el Manual sobre partenariados, es posible afirmar que la cooperación institucional marca el paso de una lógica de proyectos a una lógica de estructuras, en donde no sólo es importante la eficacia del pro-

3 Las definiciones utilizadas han sido extraídas -y en su caso adaptadas- del "Manual de gestión de evaluaciones de la cooperación española” (MAEC, 2007: 56-57). Es en el campo de la cooperación internacional para el desarrollo donde con mayor arraigo se percibe el modelo de evaluación basado en estos cinco criterios. Con algunos matices (coherencia, relevancia y sostenibilidad), también se corresponde con los promulgados por la Comisión Europea para la evaluación de las políticas de desarrollo regional y de las

176 actuaciones cofinanciadas por los Fondos Estructurales. 
yecto, sino también la sostenibilidad de la estructura en el largo plazo (Handicap Internacional, 2002).

- En el caso de políticas y/o programas gestionados desde la cooperación entre actores, la identificación de los impactos de las intervenciones deberá focalizar, además de las personas beneficiarias, en las instituciones socias del partenariado gestor; atendiendo a aspectos tales como la modificación de las modalidades de trabajo de cada socio, la articulación de nuevas metodologías de intervención pública, o la generación de procesos de aprendizaje interinstitucionales, entre otros aspectos.

- A modo de ejemplo, destaca que en el marco de la evaluación de final de impactos de la Iniciativa Comunitaria Equal en Andalucía (SAE, 2009b) se identificaron 10 impactos principales de IC Equal en las instituciones participantes de los partenariados, entre los que destacan la creación de redes de trabajo interinstitucionales; la generación de experiencias, conocimientos y metodologías de trabajo; la formación de equipos técnicos especializados; y la generación de sinergias y puesta en común de recursos para el fomento del empleo a escala local.

- En el ámbito de la cooperación institucional, el criterio de viabilidad se relaciona con la valoración de la continuidad en el tiempo de las plataformas de gestión creadas; haciendo referencia a la sostenibilidad misma del partenariado gestor, existiendo a este respecto discrepancias entre las percepciones recabadas entre los gestores y gestoras de proyectos Equal y otras experiencias (Kjaer, 2003) sobre la necesidad de dicha viabilidad ${ }^{4}$.

A partir de esta particularización de los criterios de evaluación, se modifican, consecuentemente, las preguntas que informan cada criterio; siendo necesario complementar las cuestiones tradicionales con nuevos interrogantes con capacidad de arrojar luz sobre las especificidades del modelo de gestión y su incidencia en el cumplimiento de los objetivos planteados.

A continuación se presenta una relación de preguntas "tradicionales" y "complementarias” para cada criterio de evaluación antes mencionado.

4 En relación a la viabilidad/sostenibilidad de las plataformas de gestión en partenariados creadas, Kjaer (2003) expresa que a pesar de que los outcomes sostenibles del partenariado son esenciales, la necesidad de la existencia del partenariado en perpetuidad no es necesariamente cierta. En lugar de esperar que las estructuras de los partenariados existentes sean fijas y sostenibles, puede ser más apropiado verlos como una oportunidad de cambio, caracterizados por su temporalidad y su naturaleza transitoria. Las actividades de los partenariados han de dirigirse a lograr un impacto sostenible, pero el partenariado en sí mismo puede disolverse, después de haber servido a su propósito, o de manera alternativa, transformarse en nuevas formas de operación con un cambio radical de objetivos, propósitos, o incluso socios. 


\section{CUADRO 7}

\section{Segunda etapa del proceso evaluador: redefinición de criterios}

\begin{tabular}{|l|l} 
PREGUNTAS DE EVALUACIÓN TRADICIONALES & PREGUNTAS DE EVALUACIÓN COMPLEMENTARIAS \\
(COOPERACIÓN INSTITUCIONAL)
\end{tabular}

\section{EFICIENCIA}

¿Se han respetado los presupuestos establecidos inicialmente?

¿Se han respetado los cronogramas y tiempos previstos?

¿Ha sido eficiente la transformación de los recursos en los resultados?

¿Se han previsto mecanismos para coordinar los recursos (humanos, técnicos, financieros) de los que disponen los socios?

¿Se ha convocado a todos los actores clave del territorio a los fines de generar sinergias y evitar duplicidades?

¿Se han previsto mecanismos para flexibilizar las asignaciones presupuestarias, adaptándolas a las cambiantes problemáticas/necesidades de los/as beneficiarios/as?

\section{EFICACIA}

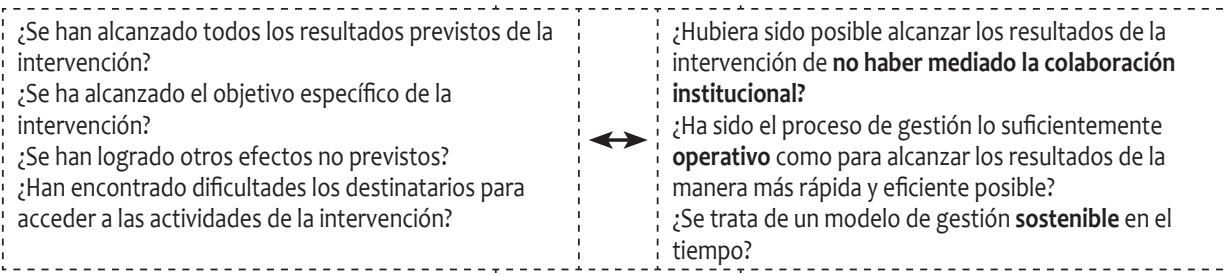

IMPACTO
I iHa contribuido la intervenciona

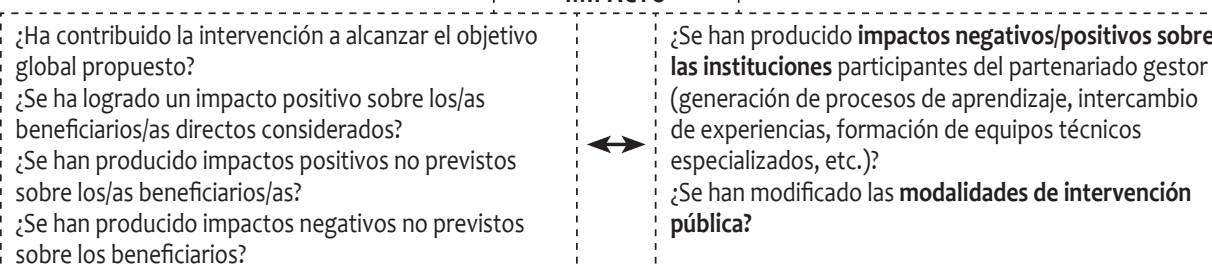
sobre los beneficiarios?

VIABILIDAD

\begin{tabular}{|l|l|l|}
\hline ¿Se mantienen los beneficios de la intervención una & & ¿Se han previsto mecanismos para mantener la acción \\
\hline vez retirado el financiamiento? & & del partenariado en el tiempo? \\
¿Se siguen generando los recursos necesarios para el & & ¿Se siguen generando los recursos necesarios para el \\
mantenimiento de las actividades? & & mantenimiento de la acción del partenariado? \\
¿Se ha influido positivamente sobre la capacidad & & \\
institucional? & $\leftrightarrow$ & \\
¿Se ha actuado sobre la desigualdad de género? & & \\
¿Se ha promovido un progreso tecnológicamente & & \\
apropiado? & & \\
¿Se ha velado por la protección de medio ambiente? & &
\end{tabular}

178 Fuente: Elaboración propia. 


\subsection{Nuevos ámbitos de evaluación}

La valoración de políticas o programas gestionados desde la acción de un partenariado impone centrar la atención en nuevos ámbitos de análisis puesto que aparecen nuevos aspectos con significativo potencial para condicionar el logro de los objetivos planteados. Dicho de otro modo, en el marco de las evaluaciones de modelos de gestión basados en la colaboración institucional entran en escena factores no tradicionales que inciden directamente en las cuestiones de evaluación y en los criterios antes mencionados. Entre ellos, cobran especial relevancia la estructura organizativa y de coordinación, lo que conlleva la valoración de aspectos tales como:

- Los mecanismos de comunicación articulados.

- Las modalidades de asignación de tareas y responsabilidades implementadas.

- Los sistemas de toma de decisiones adoptados.

- La puesta en marcha de una instancia transversal de coordinación.

Estos cuatro sub-ámbitos de análisis pueden determinar, en gran parte, el correcto funcionamiento del modelo de gestión en partenariados; condicionando, consecuentemente, la sostenibilidad de la plataforma de gestión creada y la capacidad del partenariado para alcanzar los objetivos planteados.

Así, si se consideran los mecanismos de comunicación de manera individual, se observa la posible coexistencia de tres tipologías de flujos de información:

1. Partenariados en los que las entidades socias reciben las comunicaciones remitidas desde un nodo (entidad) que asume las funciones de coordinación.

2. Partenariados en los que las entidades socias mantienen una actitud proactiva en materia de comunicación.

3. Partenariados en los que algunas entidades lideran la comunicación en algunas parcelas.

En este sentido, tal como expresa Mataix, las redes se caracterizan por poseer un conjunto de nodos y conexiones entre ellos, más fuertes o más débiles, y aunque no necesitan un nodo central, suelen poseerlo, variando su vinculación con el resto de nodos. A diferencia de las redes sociales (entre individuos), las redes organizativas (entre entidades) se caracterizan, por su carácter productivo, generando productos y resultados o prestando servicios. Su eficacia respecto a modelos de gestión tradicionales jerárquicos radica en que son más flexibles, modulares y ágiles (Mataix, 2007).

En cuanto a las modalidades de asignación de tareas y responsabilidades, resulta importante centrar el análisis en dos cuestiones clave: por un lado, en los criterios que guían la asignación de funciones y, por otro, en las modalidades mediante las cuales 
se asignan las tareas y responsabilidades, pues ambas cuestiones pueden presentar una significativa incidencia en la eficacia de los partenariados, condicionando su capacidad para alcanzar los objetivos planteados.

A priori, es posible diferenciar cinco "criterios-guía” en la asignación de tareas y responsabilidades en el marco de instancias de gestión asociada, criterios que no son excluyentes:

- Asignación de tareas en función del grado de implicación de cada entidad desde el inicio del proyecto.

- Asignación de tareas en función de las capacidades y especialidad de cada entidad.

- Asignación de tareas en función del colectivo o sector que cada entidad representa.

- Asignación de tareas en función de la experiencia de la entidad en ese ámbito o en el desarrollo de ese tipo de tareas.

- Asignación de tareas en función de la capacidad de contacto e interacción de cada entidad con los/las beneficiarios/as, así como según su estructura, recursos y experiencia.

Independientemente de estos criterios, también es importante analizar las modalidades de asignación de tareas y responsabilidades entre las entidades que conforman el partenariado, especialmente por su incidencia diferenciada en la generación de compromisos dentro del partenariado y, consecuentemente, en la continuidad/ viabilidad de los modelos de gestión basados en la colaboración institucional.

Para ilustrar estas modalidades, y su diferenciado nivel de incidencia, se recurrirá a un ejemplo que se muestra en el siguiente recuadro.

\section{CUADRO 8}

Modalidades de gestión compartida de actuaciones Modalidad 1: Acciones encadenadas.

o Las tareas se asignan sobre la base de una misma actividad, promoviendo el desarrollo conjunto de cada acción prevista en el proyecto (gestión compartida)

Ejemplo: desarrollo de una acción formativa

\begin{tabular}{|c|c|c|}
\hline Socio A & Socio B & Socio C \\
\hline $\begin{array}{c}\text { Captación del } \\
\text { alumnado }\end{array}$ & $\begin{array}{c}\text { Desarrollo de } \\
\text { contenidos }\end{array}$ & $\begin{array}{c}\text { Impartición del } \\
\text { curso }\end{array}$ \\
\hline
\end{tabular}

Fuente: Elaboración propia. 


\section{CUADRO 9}

Modalidad 2: Acciones globales.

Las tareas se dividen sobre la base de diversas "acciones tipo", en donde cada entidad asume el desarrollo de todas las tareas que dan forma a una actividad concreta, en la que no participa el resto de entidades (gestión repartida)

Ejemplo: desarrollo de una política de fomento del autoempleo
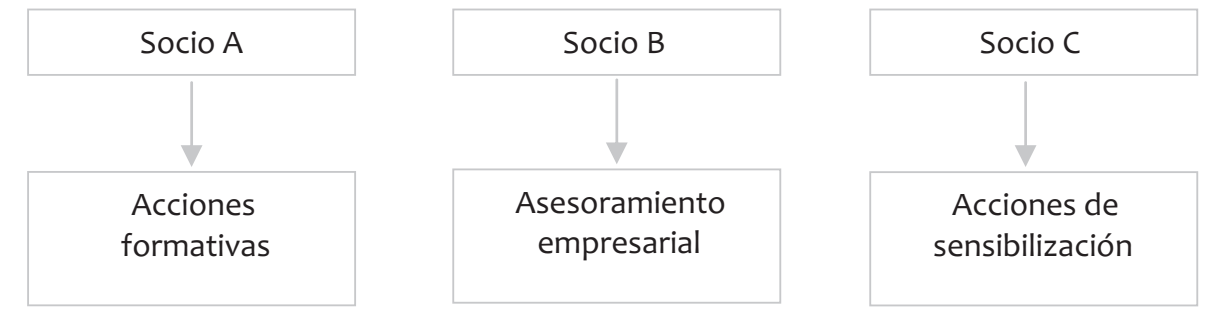

Fuente: Elaboración propia.

En el marco de Equal, la primera de estas dos modalidades -basada en la asignación de acciones encadenadas- ha resultado ser más eficaz en lo que respecta a la operatividad del partenariado. Ello se debe principalmente a su capacidad para generar compromisos horizontales entre las entidades, ya que el desarrollo de una actividad estaba supeditado al trabajo conjunto de los socios.

Por el contrario, el sistema de asignación de tareas basado en el reparto de acciones globales ha desincentivado, en cierta medida, la interacción entre las entidades, pues el desarrollo de cada acción no guardaba relación con el resto de actividades planificadas (SAE, 2009b). En estos casos, la intensidad de los lazos de colaboración puede no ser significativa; comprometiendo, en cierto modo, la continuidad de la plataforma de cooperación creada.

A su vez, en numerosas ocasiones, estas entidades pueden terminar actuando en compartimentos estancos; traduciéndose en una parcelación de la realidad de cada persona beneficiaria de las actuaciones y en una merma del tratamiento integral de las problemáticas y de sus soluciones.

De esto se desprende una de las principales limitaciones de la gestión en partenariados, centrada en las dificultades para generar compromisos duraderos entre los miembros de la red; lo cual, por un lado, afecta la viabilidad/sostenibilidad del modelo de gestión en el tiempo; y, por otro, condiciona el logro de los objetivos planteados, limitando la eficacia de las actuaciones ${ }^{5}$.

5 La pregunta en este caso es si realmente es importante y necesaria la sostenibilidad del modelo de gestión. Algunos autores afirman que la sostenibilidad del partenariado constituye un requisito hasta 
Esta dificultad para generar compromisos se relaciona de manera directa con la diferenciación, proveniente del campo de las relaciones internacionales, entre los conceptos intergubernamental y supranacional, que en línea con las cuestiones hasta ahora abordadas podrían expresarse como cooperación interinstitucional y cooperación suprainstitucional. Así, mientras el primer concepto hace referencia a un proceso que afecta a varias instituciones que voluntariamente deciden emprender un proyecto juntas; el segundo implicaría la existencia de una institución que estaría por encima de las otras, cuyas decisiones deberían ser acatadas por el resto de instituciones.

Evidentemente, el sistema de gestión en partenariado al que se viene haciendo referencia es de base interinstitucional, sustentándose exclusivamente en la voluntariedad de las entidades que conforman cada partenariado; lo que al tiempo que supone importantes ventajas en cuanto al carácter democrático del modelo de gestión, plantea ciertos interrogantes respecto de la fortaleza del modelo como generador de compromisos duraderos.

En cuanto a los sistemas de toma de decisiones adoptados, el estudio de diversas experiencias de cooperación pone en evidencia que resulta fundamental la articulación consensuada de un sistema de carácter horizontal; en tanto que se ha demostrado que la reproducción de prácticas verticales en este sentido atenta contra los principios mismos de la colaboración institucional, desincentivando la continuidad de las estructuras de cooperación creadas, y afectando de manera directa la viabilidad de este modelo de gestión.

Asimismo, resulta importante considerar, en el marco de las modalidades de coordinación articuladas, un último sub-ámbito de análisis: la existencia de una instancia de coordinación. Y la importancia de focalizar el análisis en este aspecto radica en que un rol de coordinación fuerte supone un factor facilitador del trabajo en red, incidiendo de manera directa en la generación y el mantenimiento de los lazos de cooperación. En el caso de Equal existía un rol de representación (normalmente ostentado por la Consejería de Empleo de la Junta de Andalucía) y un rol de coordinación asumido por la entidad que lideraba el proyecto. A este respecto, los representantes de las instituciones participantes relacionaron, de manera directa, la mayor/menor presencia de la Consejería de Empleo con la intensidad del trabajo en red; evidenciándose lazos más intensos en aquellos casos en los que el rol de la Consejería de Empleo (a través de sus distintas delegaciones) se percibía como "más activo".

tanto dure la intervención o política; careciendo de importancia la continuidad del modelo de gestión una vez finalizada la intervención. No obstante, los participantes en partenariados de la Iniciativa Equal en Andalucía que fueron entrevistados muestran que una dimensión de la eficacia de dichos partenariados es su capacidad para mantenerse en el tiempo, justificado por las sinergias que se hubiesen generado o por la mejora del servicio prestado y al margen de los incentivos económicos que pudiesen haber constituido el estimulo inicial de la cooperación. 


\section{CUADRO 10}

Tercera etapa del proceso evaluador. Nuevos ámbitos de evaluación: estructuras organizativas y modalidades de coordinación

\begin{tabular}{|c|c|c|}
\hline Sub-ámbitos de análisis & Factores de incidencia & Criterios afectados \\
\hline $\begin{array}{l}\text { Mecanismos de } \\
\text { comunicación }\end{array}$ & $\begin{array}{l}\text { Tipología de flujos de } \\
\text { información ad-intra } \\
\text { partenariado }\end{array}$ & Eficacia \\
\hline \multicolumn{3}{|c|}{ Modalidades de asignación de tareas y responsabilidades } \\
\hline Criterios de asignación & $\begin{array}{l}\text { En función de grado de } \\
\text { implicación desde el inicio } \\
\text { Según capacidades } \\
\text { Según colectivo o sector que } \\
\text { representa } \\
\text { Según experiencia } \\
\text { Según capacidad de contacto e } \\
\text { interacción }\end{array}$ & \\
\hline $\begin{array}{l}\text { Modalidades de } \\
\text { asignación }\end{array}$ & $\begin{array}{l}\text { Acciones encadenadas } \\
\text { Acciones globales }\end{array}$ & $\begin{array}{l}\text { Eficacia } \\
\text { Eficiencia } \\
\text { Viabilidad } \\
\text { Impacto }\end{array}$ \\
\hline $\begin{array}{l}\text { Sistemas de toma de } \\
\text { decisiones }\end{array}$ & $\begin{array}{l}\text { Carácter horizontal del sistema } \\
\text { Carácter vertical del sistema }\end{array}$ & $\begin{array}{l}\text { Eficacia } \\
\text { Viabilidad }\end{array}$ \\
\hline Instancia de coordinación & Facilita/ralentiza el proceso & $\begin{array}{l}\text { Eficacia } \\
\text { Viabilidad } \\
\text { Impacto }\end{array}$ \\
\hline
\end{tabular}

Fuente: Elaboración propia.

Por último, no hay que olvidar que la cooperación institucional además de un modelo de gestión que debe ser enjuiciado en función de su contribución al logro de los objetivos generales de la intervención, puede constituir en sí mismo un objetivo instrumental de las políticas públicas para promover mayores cotas de desarrollo y bienestar. En este caso, la promoción de la cooperación institucional se convierte en un objetivo de las intervenciones; adquiriendo una connotación diferente a la que se ha venido exponiendo hasta ahora. Así, es posible diferenciar dos significados diferenciados de la cooperación institucional que merecen ser tenidos en cuenta durante los procesos de evaluación, en tanto que ostentan capacidad para 
informar sobre algunas cuestiones clave en un contexto de desarrollo socioeconómico de base local:

- La cooperación institucional como modelo de gestión de las políticas públicas, cuyo análisis puede arrojar lecciones valiosas que contribuyan a definir consensuadamente un nuevo modelo de gobernanza que facilite la vertebración de políticas públicas territoriales.

- La colaboración institucional como objetivo de las políticas públicas, cuya evaluación puede aportar insumos sobre aquellos elementos que necesariamente deben estar presentes si lo que se persigue es generar procesos de cooperación territorial.

En este segundo caso, emergen nuevas categorías de análisis como las que siguen:

- El carácter movilizador de las políticas, entendido como su capacidad para dinamizar a todos los actores necesarios para acometer el objetivo de cooperación planteado.

- El grado de participación de los actores clave del territorio en el diseño del objetivo planteado (independientemente de su participación en el partenariado).

- La sostenibilidad del partenariado promovido, es decir, su capacidad para asegurar la continuidad de las instancias de cooperación creadas una vez finalizada la intervención o reproducirlas bajo otras fórmulas de colaboración.

- La existencia de voluntad política para acompañar/liderar el proceso.

La promoción de la colaboración institucional como un objetivo de los proyectos constituye uno de los aspectos más destacables de la Iniciativa Equal en Andalucía, en tanto en cuanto se ha utilizado esta fórmula experimental para fomentar la generación de procesos de cooperación duraderos a nivel territorial.

Tal como se expresa en el informe de evaluación de las redes de cooperación establecidas en el marco del Equal en Andalucía, "las ventajas de este tipo de acciones son muchas. Entre ellas destaca principalmente la articulación de escenarios de reflexión colectiva; la posibilidad de poner en común diagnósticos y de contar con estrategias más innovadoras para el desarrollo de estos territorios; la mayor complementariedad de las actuaciones; la optimización en el uso de los recursos; y la articulación de mecanismos capaces de responsabilizar horizontalmen184 2009b: 171-172). 


\section{CUADRO 11}

La cooperación institucional como modelo de gestión y como objetivo: significado, funciones, nuevos ámbitos de evaluación y contenidos de la información

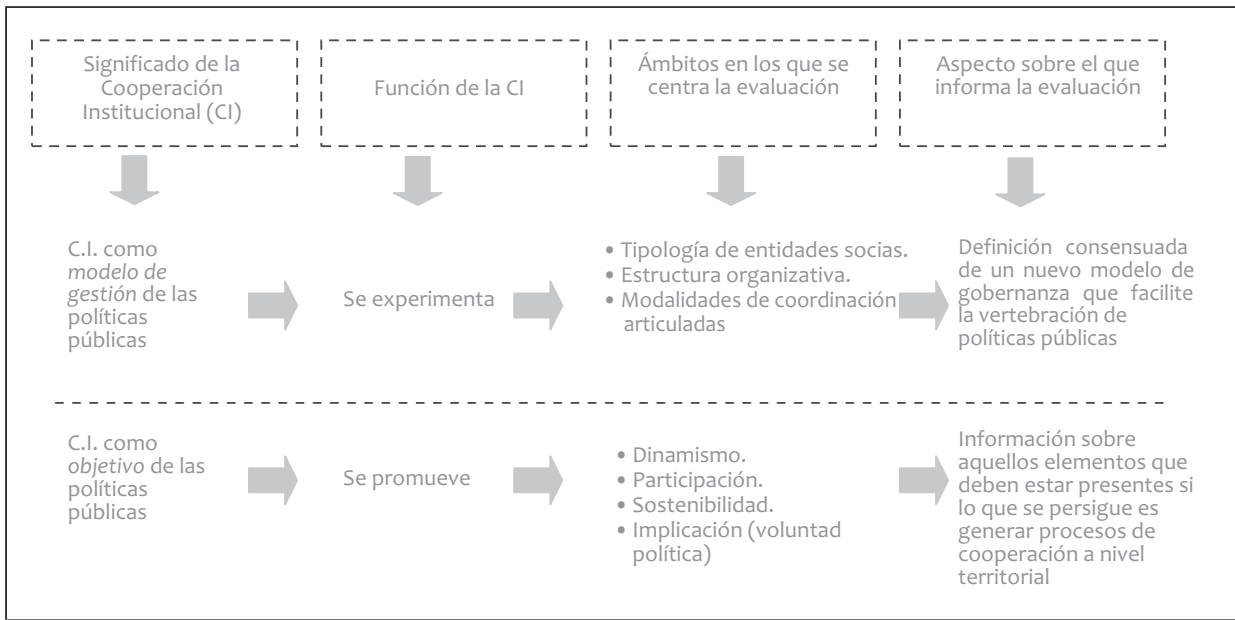

Fuente: Elaboración propia.

\subsection{Identificación de metodologías de análisis adecuadas}

La evaluación de modelos de gestión basados en la colaboración institucional requiere, por último, la identificación de metodologías de análisis adecuadas; capaces de alimentar, de manera simultánea, dos requerimientos de información paralelos: por un lado, los centrados exclusivamente en los resultados e impactos de la intervención (estrategia operativa de las políticas); y, por otro, aquellos que focalizan en los mecanismos de gestión articulados desde la red para alcanzar estos resultados e impactos (estrategia institucional de las políticas).

En este sentido, mientras en el primer caso las metodologías de análisis sustentadas en técnicas de investigación cuantitativas pueden aportar gran parte de los datos necesarios para llevar adelante la evaluación, en el segundo se precisará de información de carácter cualitativo, capaz de aportar datos sobre las particularidades, ventajas y desventajas del modelo de gestión implementado, siempre con relación a un contexto determinado, a destinatarios/as específicos/as y a objetivos diferenciados.

Sobre la base de esta doble necesidad de información, algunas metodologías de análisis muestran mayor capacidad de adaptarse a la evaluación de modelos de gestión basados en la cooperación institucional.

Una primera referencia estaría relacionada con la combinación de modelos de evaluación basados en estándares (criterios) con modelos de evaluación comprensi- 
vos (Stake, 2006) ya que, desde nuestra experiencia, de este planteamiento ecléctico emerge una mejor comprensión de los hechos y hallazgos de la evaluación de partenariados. Todas las referencias presentadas en el apartado 3.3 sobre la particularización de cuestiones y criterios de evaluación, darían respuesta a los requerimientos que impone un modelo de evaluación basado en estándares. Por su parte, las necesidad de comprender la bondad y utilidad de los procesos de colaboración institucional en el seno del partenariado nos han hecho adoptar en la evaluación de Equal (SAE, 2009b), además de estos preceptos, los postulados de la evaluación comprensiva propuesta por Stake, y han tenido su traducción en el proceso evaluativo en el desarrollo de técnicas cualitativas (observación participante, historias de vida y talleres de participación estratégica con personas beneficiarias y gestores/as) como base que ha permitido comprender que decisiones se tomaron dado el contexto que se enfrentaba, y han servido de base para la construcción de cuestionarios que permitieron ponderar dichas percepciones cualitativas en cada uno de los proyectos analizados.

Además de este planteamiento ecléctico, entre las aproximaciones metodológicas que pueden guiar la evaluación de partenariados, destaca en primer lugar el enfoque de Evaluación basado en la teoría y la denominada teoría del programa, centrada en la explicitación de la "caja negra"; es decir, en el análisis de las causas o razones que motivan que un determinado cambio ocurra (Weiss, 1998). La teoría del programa indaga, además, en los mecanismos subyacentes que se presumen como responsables de dichos cambios -relaciones causa-efecto- (Bustelo, 2007). El postulado sobre el que se construye esta aproximación es que si se consigue establecer cuáles son los factores determinantes del éxito, y la forma en que se interrelacionan, se puede decidir qué pasos deben supervisarse a medida que avanza el programa, para determinar si encuentran confirmación en los hechos (Banco Mundial, 2004).

Junto con la teoría de la implementación, forman lo que Weiss denomina Teorías del cambio. La teoría de la implementación se centra en las actividades desarrolladas para alcanzar los objetivos y en cómo se aplican; mientras que la teoría del programa aborda las respuestas que dichas actividades generan, mediante el aporte de un modelo o teoría explícita de cómo y por qué el proyecto produce los efectos planeados (Díez, 2007). Ambas vertientes son especialmente relevantes en una evaluación de partenariados.

En este sentido, el análisis pormenorizado del modelo de gestión en partenariado se correspondería con la explicitación de la caja negra, permitiendo identificar ciertos factores (catalizadores) asociados a la gestión de las políticas con capacidad para potenciar/desincentivar el logro de los objetivos planteados.

Chen avanza un paso más en los postulados de la teoría del programa, incluyendo el concepto de moderadores, haciendo referencia a aquellos factores -especialmente relacionados con las modalidades de implementación de un programa- que 186 condicionan los efectos y/o resultados de una intervención (Chen, 2005). 
Los nuevos ámbitos de evaluación antes analizados (estructura organizativa implantada y modalidades de coordinación articuladas, junto con el análisis de la tipología de entidades socias que conforman el partenariado, el rol que juega cada una de ellas y las relaciones informales de colaboración que se generan) se erigen -entre otros- como posibles factores moderadores dentro de un modelo de gestión asociada; afectando a los efectos y/o resultados de la intervención.

En segundo lugar, destaca la metodología del análisis de redes sociales, centrada en el funcionamiento de estas estructuras reticulares de gestión. En este sentido, siguiendo a Garrido, se entiende por red social -como categoría de análisis- a los vínculos entre un conjunto definido de entidades sociales, implicando esto que los vínculos existentes entre los elementos cumplen determinadas propiedades que repercuten sobre los aspectos de las conductas de los actores. Tales propiedades (intensidad relacional, posición del actor, accesibilidad, cliqués, grupos de equivalencia estructural, etc.) definen la función o funciones de una red social (Garrido, 2003).

En el marco del análisis de redes, resulta interesante también centrar la atención en aquellos actores que cumplen las funciones de coordinación o intermediación, lo cual puede arrojar luz sobre los flujos de comunicación principales que tienen lugar en el interior de la red, facilitando su correcto funcionamiento. En palabras de Borras, "se entiende por intermediación (brokerage) la posición intermedia que adopta un actor entre otros dos agentes, que son denominados respectivamente el remitente y el receptor" (Borras, 2009: 24).

También resulta pertinente considerar la utilización de metodologías de análisis y medición del capital social, definido como la "capacidad que tiene el [tejido institucional] para adquirir información (técnica, organizativa, comercial, financiera, etc.), incorporarla a procesos propios y gestionar tales procesos, obteniendo como resultado una mayor innovación y desarrollo [institucional]" (Román, 2001: 16).

Para medir el capital social, Román y Rodríguez (2004) proponen un sistema de indicadores que contempla los siguientes descriptores:

Indicadores de recursos: dimensiones de capital social:

- Redes

- Confianza

a) confianza generalizada

b) confianza particularizada

- Normas, actitudes y valores

- Calidad del marco institucional 
Indicadores de realización: mecanismos:

- Acceso e intercambio de información

- Acciones colectivas

Indicadores de resultados:

- Generar conocimiento

- Innovación

- Desarrollo empresarial

- Crecimiento del empleo

Finalmente, es posible mencionar otras metodologías de análisis centradas en la doble vertiente operativa-institucional que caracteriza a los modelos de gestión en partenariado, como los estudios de las coaliciones comunitarias desde el campo de la psicología (Martínez y Martínez, 2003) o la aplicación del enfoque sistémico (utilización del concepto de sistema como un todo irreducible: estructura-estrategia-procesos).

En todas estas aproximaciones, las metodologías de análisis deberán apoyarse en técnicas de investigación adecuadas, capaces de recoger información cuantitativa y cualitativa que permita comprender y valorar de la manera más exhaustiva posible las estrategias institucionales que dan forma a la acción del partenariado. Entre ellas, destacan los grupos de discusión, los talleres de participación estratégica, las entrevistas en profundidad, los grupos focales, las historias de vida, la observación participante y los estudios de casos (Stake, 1997).

Atendiendo a las consideraciones metodológicas que orientaron la evaluación de las redes de cooperación en Equal en Andalucía, para examinar las modalidades de gestión asociada desplegadas en el seno de las agrupaciones de desarrollo se siguieron los postulados de la teoría del programa, haciendo uso de herramientas de carácter cualitativo y cuantitativo, y recurriendo, asimismo, a técnicas propias de los estudios de caso y de la metodología de análisis de redes (ver consideraciones metodológicas en SAE, 2009a y 2009b).

Así, se comenzó por explorar las experiencias de cooperación institucional desarrolladas desde cada una de las agrupaciones de desarrollo gestoras de proyectos durante la segunda convocatoria de Equal (2005-2007). Este examen se llevó a cabo mediante el análisis documental, la realización de entrevistas semiestructuradas, la autoadministración de un cuestionario de autoevaluación y la celebración de talleres de participación estratégica, que permitieron identificar modelos de cooperación que posteriormente fueron objeto de estudios de caso, así como factores clave de éxito o fracaso de las modalidades de colaboración 188 implementadas. 
CUADRO 12

Cuarta etapa del proceso evaluador: identificación de metodologías de análisis adecuadas

\begin{tabular}{|c|c|c|c|}
\hline $\begin{array}{l}\text { Metodología } \\
\text { de análisis }\end{array}$ & Foco de estudio & Técnica de investigación & $\begin{array}{l}\text { Aspectos sobre los } \\
\text { que informa }\end{array}$ \\
\hline $\begin{array}{l}\text { Teoría del } \\
\text { programa }\end{array}$ & $\begin{array}{l}\text { Caja negra del } \\
\text { programa, análisis de } \\
\text { relaciones causa-efecto. } \\
\text { Moderadores }\end{array}$ & \multirow{3}{*}{$\begin{array}{l}\text { - Grupos de discusión } \\
\text { - Talleres de } \\
\text { participación } \\
\text { estratégica } \\
\text { - Entrevistas en } \\
\text { profundidad } \\
\text { - Grupos focales } \\
\text { - Observación } \\
\text { participante }\end{array}$} & $\begin{array}{l}\text { Factores } \\
\text { determinantes del } \\
\text { éxito o fracaso de las } \\
\text { intervenciones (con } \\
\text { capacidad para } \\
\text { potenciar/ } \\
\text { desincentivar el logro } \\
\text { de los objetivos } \\
\text { planteados) }\end{array}$ \\
\hline $\begin{array}{l}\text { Análisis de } \\
\text { redes } \\
\text { sociales }\end{array}$ & $\begin{array}{l}\text { Vínculos entre las } \\
\text { entidades sociales que } \\
\text { conforman la red } \\
\text { (intensidad relacional, } \\
\text { posición del actor, } \\
\text { accesibilidad, cliqués, } \\
\text { grupos de equivalencia } \\
\text { estructural, etc.) }\end{array}$ & & $\begin{array}{l}\text { Funciones de una red } \\
\text { social }\end{array}$ \\
\hline $\begin{array}{l}\text { Análisis y } \\
\text { medición } \\
\text { del capital } \\
\text { social }\end{array}$ & $\begin{array}{l}\text { Redes; confianza; } \\
\text { normas, actitudes y } \\
\text { valores; calidad del } \\
\text { marco institucional }\end{array}$ & & $\begin{array}{l}\text { Acceso e intercambio } \\
\text { de información; } \\
\text { acciones colectivas; } \\
\text { generación de } \\
\text { conocimiento; } \\
\text { innovación; desarrollo } \\
\text { empresarial; } \\
\text { crecimiento del } \\
\text { empleo }\end{array}$ \\
\hline
\end{tabular}

Fuente: Elaboración propia.

En el cuestionario de autoevaluación se solicitaba a las entidades coordinadoras de los proyectos que examinasen la gestión del partenariado y valorasen la cooperación mantenida con el resto de entidades socias según diversas modalidades o temáticas (diseño del proyecto, gestión de actividades, prestación de servicios, evaluación, financiación o toma de decisiones, entre otras). Además de esta valoración de la cooperación se incluyeron indicadores básicos sobre el proyecto y el partenariado, sobre la utilidad de los mecanismos de comunicación propuestos, sobre la pertinencia del partenariado gestor atendiendo al perfil de las entidades socias y al nivel de participación de cada una de ellas y sobre las modalidades de asignación de tareas y responsabilidades. 
La autoevalaución que cada entidad realizó sobre las relaciones de cooperación mantenidas con el resto de entidades socias del partenariado, permitió construir Diagramas de colaboración institucional en los que se mostraba el mapeo de las redes de trabajo habilitadas en el seno del partenariado en los distintos ámbitos que conforman la gestión de un proyecto de empleo (financiación, diseño, ejecución, seguimiento y evaluación, entre otras), según la tipología de entidad socia (asociación, administración local, agente social) y el nivel de participación registrado en las autoevaluaciones. Al poner en relación las diferentes modalidades de cooperación se observaron hechos relevantes que ponían de manifiesto, por ejemplo, que determinada tipología de entidades participaba más activamente en la toma de decisiones si había registrado un nivel alto de participación en el diseño del proyecto.

\section{CUADRO 13}

Modelo de diagrama de colaboración institucional

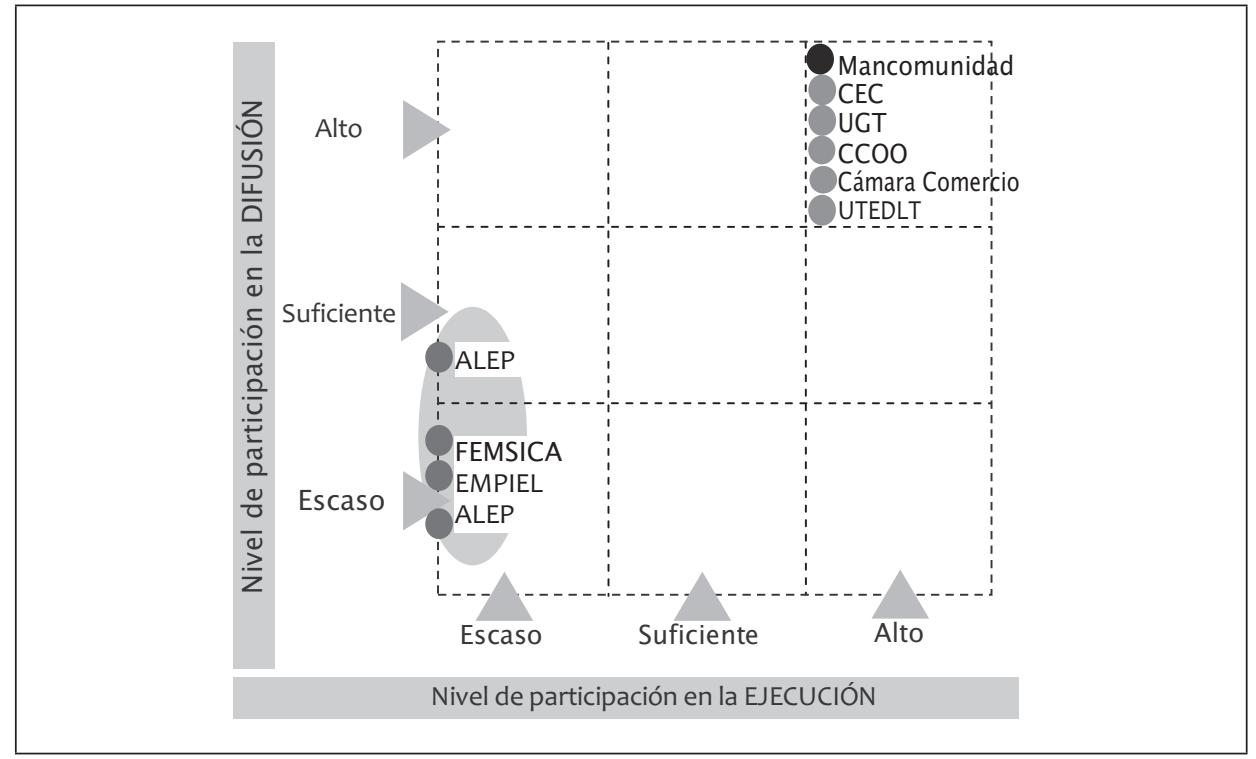

Fuente: SAE, 2009-1: 19.

El cuestionario de autoevaluación y los diagramas de colaboración se inspiran en enfoque del análisis de redes sociales, que se utilizó para determinar las relaciones entre las entidades socias, la estructura de la red que configuran y su funcionamiento ${ }^{6}$.

6 Este enfoque, al centrarse en las relaciones y no en los sujetos que las mantienen, lleva en última instancia a una aproximación a la medición o delimitación de la generación de capital social, como recurso empleado/generado en el proceso de compartir información y conocimiento (Román, 2001). Si Román define y utiliza el concepto de capital social como la capacidad de un grupo para compartir información, generar conocimiento y aplicarlo al proceso productivo, en este tipo de evaluaciones de partenariados Equal se hace referencia a la capacidad del partenariado para compartir información, generar conocimien- 
La aplicación de estas técnicas permitió detectar modelos de cooperación, elementos que los caracterizaban, factores determinantes en la gestión y resultados e impactos percibidos que, en su conjunto, fueron trasladados a un cuestionario para que los representantes de cada proyecto (entidad coordinadora) pudiesen ponderar en qué medida dichos factores se correspondían con la realidad de la agrupación de desarrollo en la que participaron.

El análisis agregado de la información recabada a nivel de proyecto permitió una primera aproximación sobre los distintos elementos que determinan un modelo de gestión basado en la colaboración institucional:

- La tipología de entidades socias, focalizando el análisis en las entidades socias y sus roles, la aparición de actores "no tradicionales" en la gestión de las políticas de empleo, la adecuación entre las entidades socias y los objetivos planteados desde los proyectos, entre otros aspectos.

- Su estructura organizativa.

- Los mecanismos de coordinación, comunicación, asignación de tareas y toma de decisiones implementados.

- La capacitación representativa y participativa.

Finalmente, estos elementos fueron analizados en una serie de partenariados que respondían a modalidades particulares de redes de cooperación y que fueron objeto de estudios de caso, que tenían como finalidad valorar la eficacia del partenariado con respecto a los modelos de gestión de las políticas de empleo tradicionales. Para ello, se procedió a la realización de talleres de participación estratégica y de entrevistas en profundidad con una muestra de entidades socias los partenariados seleccionados. Estos talleres estuvieron orientados a la comprensión de las percepciones de una muestra de actores clave de los partenariados sobre la utilidad y oportunidad de los mecanismos de colaboración institucional impulsados a través de Equal sobre la plataforma de agrupaciones de desarrollo. Entre los aspectos tratados se focalizó en la pertinencia y eficacia de la metodología de trabajo que supuso la gestión a través de agrupaciones de desarrollo, prestando especial atención a aspectos tales como:

- Mecanismos de coordinación y asignación de tareas implementados.

- Incidencia de la colaboración institucional en el logro de los objetivos planteados.

- Operatividad de la gestión del partenariado.

- Sostenibilidad de la acción del partenariado.

- Ventajas y desventajas de la gestión del partenariado.

to y aplicarlo a la mejora de las políticas de empleo e inserción sociolaboral en las que se encuadra la Iniciativa Comunitaria. 
En este proceso se observaron las distintas connotaciones que adquiría el concepto de eficacia de la colaboración institucional experimentada. Así, fue posible identificar y analizar tres aspectos a partir de los cuales las entidades socias valoraron la eficacia de los modelos de cooperación desarrollados:

1. La operatividad del proceso de gestión en el que se materializó la colaboración institucional.

2. La capacidad de los partenariados para conseguir los objetivos planteados.

3. La sostenibilidad de la acción del partenariado.

Finalmente, se procedió al análisis de los impactos que ha generado la acción del partenariado en las instituciones participantes en las agrupaciones de desarrollo; siendo el objetivo extraer aprendizajes que informen y optimicen futuras intervenciones en materia de empleo.

\section{RECOMENDACIONES PARA LA CONSTRUCCIÓN Y PROMOCIÓN DE PARTENARIADOS EFICACES}

Entre las estrategias para la mejora continua en el ámbito de la evaluación de políticas públicas se encuentran el desarrollo de metaevaluaciones y la realización de síntesis de evaluaciones; centradas las primeras en el propio proceso evaluativo (evaluar la evaluación) y las segundas en los aprendizajes extraídos (sistematizar sus hallazgos y conclusiones). En este apartado se ha realizado un esfuerzo por sintetizar las principales conclusiones y recomendaciones la evaluación de la experiencia Equal en Andalucía en materia de redes de cooperación. Al difundir y compartir esta experiencia el propósito no es otro que contribuir a generar un background suficiente que facilite futuras síntesis de evaluaciones: sintetizar para sistematizar.

\section{Composición de los partenariados}

En primer lugar, es posible observar que en aquellos partenariados en los que existe una relación directa entre el problema que se pretende solucionar y la composición del partenariado, las personas beneficiarias expresan una mayor conformidad con las políticas, puntualizándose las ventajas de contar con actuaciones pertinentes y adaptadas a las realidades de cada individuo.

$\Rightarrow$ La existencia de una relación directa entre el problema que se pretende solucionar y la composición del partenariado permite explicitar las dificultades a resolver de manera más clara y diseñar actuaciones más selectivas y focalizadas, capaces de responder a situaciones concretas y siendo sensibles a la diversidad dentro de cada grupo poblacional o colectivo. 
Asimismo, la experiencia sugiere que la participación activa del tejido institucional local, en especial de asociaciones representativas de subgrupos específicos de la comunidad, es imprescindible si lo que se pretende es adaptar las políticas a las necesidades de las personas beneficiarias; no obstante, la experiencia también demuestra que tal nivel de implicación no resulta viable de no mediar una contraparte económica que posibilite al personal de tales organizaciones asumir compromisos en este sentido. $Y$ en esto las Administraciones Públicas deben asumir un rol protagonista, articulando medidas de apoyo tendentes a fomentar la participación activa de estas entidades.

En el marco de la evaluación de Equal, se ha puesto de manifiesto que la representatividad de las entidades posee dos dimensiones que deben ser consideradas para constituir partenariados eficaces: una "extensiva”, que hace referencia a su implantación en el territorio y a su capacidad para representar los intereses generales de un colectivo (considerando al grupo como un todo homogéneo); y otra vertiente "intensiva", relacionada con la capacidad de las entidades para ser sensibles a las necesidades específicas de facciones o subgrupos (poniendo el énfasis en las necesidades y en el perfil que éstas configuran y que son las que determinan la diversidad dentro del grupo) $)^{7}$.

Esta representatividad de las agrupaciones de desarrollo Equal, extensiva e intensiva, se ha visto condicionada según las percepciones de las entidades colaboradoras (no ejecutoras directas de presupuesto) por la falta de recursos, que se ha traducido en su implicación desigual -y, en cierta medida, voluntarista- a lo largo del ciclo de vida de los proyectos. La constante dedicación y los requerimientos continuos de coordinación que exige el trabajo en red, ponen de relieve que la participación e implicación de este tipo de entidades en los partenariados supone un reto que exige explorar nuevas fórmulas que garanticen recursos específicos que les permitan compaginar su quehacer cotidiano con la asunción de compromisos duraderos y efectivos con el fomento del empleo (SAE, 2009b).

$\Rightarrow$ Independientemente de estas consideraciones, es necesario encontrar un equilibrio entre la heterogeneidad institucional, como garante de la representatividad de la diversidad local, y la operatividad del procedimiento, en tanto que la existencia de un número excesivo de socios puede dificultar el buen funcionamiento del sistema de gestión implementado.

Por otra parte, siendo una finalidad de la colaboración institucional la necesidad de coordinar los distintos recursos con los que cuentan los territorios, resulta funda-

$7 \quad$ Un ejemplo de esto último lo constituye el hecho de que en un partenariado destinado a promover el autoempleo en mujeres gitanas de un barrio con problemas de exclusión social, se considera una representación más intensiva de las necesidades de dichas mujeres la presencia en el partenariado de asociaciones del propio barrio, de asociaciones de mujeres o, mejor incluso, de asociaciones de mujeres gitanas de dicho barrio si es que existen. Sería menos intensiva, a priori, la representación que pudiese ostentar una agrupación regional de empresarios y una agrupación regional de personas gitanas en general. 
mental que en los partenariados se cuente con la participación activa de todos los actores clave en las materias que motivan las políticas. En caso contrario se continúan reproduciendo estructuras paralelas, que operan desde el individualismo y no desde la construcción de sinergias. De aquí se desprende el importante papel que las Administraciones Públicas -en especial a nivel regional en el caso de Equal- deben asumir en la coordinación de los distintos actores y recursos disponibles, en tanto que ostentan la autoridad y la competencia necesarias para liderar los procesos.

Por último, resulta importante destacar las diferencias entre actores locales en los que la cooperación constituye un compromiso verdaderamente asumido por todos los estamentos institucionales, de aquellos en los que la cooperación sólo constituye una prioridad para los equipos técnicos. En el caso de Equal la experiencia se relaciona más directamente al segundo caso. Esta brecha político-técnica ha afectado de manera acusada a la sostenibilidad de los procesos de cooperación generados que, en gran parte, está condicionada a la voluntad política de los directivos y cargos electos (SAE, 2009b).

\section{Diseño de las intervenciones}

En esta fase, la existencia de objetivos comunes entre los socios, que precedan a la constitución del partenariado o que se diseñen conjuntamente mediante un proceso participativo, ha demostrado ser un elemento facilitador del proceso de colaboración; lo que puede lograrse reforzando los mecanismos de participación durante el diseño de las intervenciones, reemplazando los sistemas de consulta por estrategias genuinas de trabajo en red y destinando partidas presupuestarias a la promoción de una mayor acción conjunta en la fase de diseño.

Por otra parte, la articulación de canales claros y accesibles de comunicación entre los miembros del partenariado también ha demostrado su potencial para garantizar la operatividad de los procesos. En el caso de Equal el éxito del trabajo en red, medido a través del logro de los objetivos planteados y de la continuidad de los lazos de cooperación generados, ha sido más tangible en aquellos casos en los que las comunicaciones fluyeron de manera constante; siendo a la vez fundamental el rol de coordinación para mantener vivo el proceso (SAE, 2009b).

\section{Ejecución de las intervenciones}

En esta fase, el modo en el que se han implementado dos mecanismos clave ha marcado diferencias en cuanto a la eficacia de la acción del partenariado. Concretamente, se hace referencia a los mecanismos de asignación de tareas y responsabilidades y los procedimientos de toma de decisiones.

En cuanto a los primeros, el reparto de tareas basado en la asignación de accio-

194 nes encadenadas resultó ser más eficaz que la modalidad de asignación de acciones 
globales, especialmente en relación a la operatividad de la acción del partenariado. Y esto principalmente por su capacidad para generar compromisos horizontales entre los socios, en tanto el desarrollo de una actividad está supeditado al trabajo conjunto de todas las entidades participantes. Por el contrario, el sistema de asignación de tareas basado en el reparto de acciones globales puede desincentivar, en cierta medida, la interacción entre las entidades; pues el desarrollo de cada acción no guarda relación con el resto de actividades planificadas.

En esta misma línea de pensamiento, ha mostrado ser fundamental la articulación consensuada de un sistema horizontal de toma de decisiones; en tanto que se ha puesto de relieve que la reproducción de prácticas verticalistas en este sentido atenta contra los principios mismos de la colaboración institucional, desincentivando la continuidad de las estructuras de cooperación creadas.

En el caso de Equal, el análisis y valoración individual de cada partenariado ha puesto de manifiesto que existe una relación directa entre financiación y toma de decisiones o, lo que es lo mismo, entre quien aporta cofinanciación al proyecto y entre quienes tienen capacidad de decisión; lo que muestra las limitaciones de la apertura de los partenariados hacia el resto de entidades no cofinanciadoras (SAE, 2009b) ${ }^{8}$.

De manera transversal al ciclo de vida de cada política, destaca como condicionante de la operatividad, sostenibilidad y capacidad de impacto de la acción del partenariado la existencia de voluntad política por parte de las Administraciones públicas para acompañar y liderar el proceso en tres sentidos:

1. Porque sin el apoyo de las Administraciones públicas (AAPP). disminuye notablemente la legitimidad de las intervenciones.

2. Porque el desarrollo de políticas paralelas a aquellas liderados desde la AA.PP. puede contribuir a la reproducción de prácticas simultáneas más que a la potenciación de recursos escasos.

3. Porque las posibilidades de sostenibilidad de las iniciativas de cooperación se reducen considerablemente si no se cuenta con el apoyo y liderazgo del actor protagónico en materia de políticas públicas.

4. Seguimiento y evaluación.

En este aspecto, se hace necesario contar con un instrumento -evaluación- con capacidad para reorientar las intervenciones a medio camino, potenciando así su utilidad y capacidad de impacto.

8 Hay que tener en cuenta que no todas las entidades del partenariado eran cofinanciadoras de los proyectos Equal. 
En cuanto a la función de evaluación en el seno del partenariado hay que tener en cuenta de manera preliminar que puede ser responsabilidad de una única entidad, de un grupo o del conjunto de entidades asociadas. Esta participación en la evaluación puede variar desde una implicación directa en el diseño, realización y comunicación de resultados, lo que sin duda aumenta el aprendizaje organizacional (individual y colectivo), hasta la coordinación del proceso evaluativo externalizado o su cofinanciación.

En el caso de los partenariados resulta especialmente interesante el desarrollo de evaluaciones conjuntas, entre varias o todas las entidades asociadas, aunque se observa que suele ser una de las entidades la que ostenta la responsabilidad en este proceso apoyándose en asistencias técnicas externas.

Esta situación, que en principio puede parecer adecuada, puede generar tensiones ante dificultades y retrasos en la ejecución de la intervención, ya que ello provoca que la evaluación quede relegada a un segundo plano, perdiendo la centralidad que debe tener.

Más allá de quien asume esta responsabilidad de evaluación en el partenariado la cuestión central es qué funciones son efectivamente asumidas y cuáles quedan externalizadas. Ello es así porque aunque se pueda externalizar la realización de la evaluación existen muchas decisiones que corresponden a los propios actores del partenariado y que no se pueden eludir, como la determinación de los objetivos, el ámbito, el alcance o las cuestiones a las que se debe dar respuesta con el ejercicio evaluativo (Murciano, 2006).

En cualquier caso, para la evaluación de políticas públicas, los partenariados presentan una fortaleza sobre otros modelos de gestión: reúnen a los múltiples niveles de la administración con competencias en una determinada materia y a gran parte de los stakeholders. Por tanto, a priori, se configuran como el escenario idóneo para desplegar procesos de evaluación participativos.

En el marco de la evaluación de redes de cooperación en Equal, desde las entidades participantes en las $A D$ se ha puesto de manifiesto el gran trabajo realizado en materia de seguimiento y evaluación de cara a la detección de buenas prácticas para su transferencia, contando para ello con instrumentos útiles y ágiles y generando un importante proceso de desarrollo de capacidades en este sentido.

No obstante, también han expresado el reto que aún supone desarrollar las herramientas necesarias que permitan redireccionar las actuaciones sobre la marcha. En unos casos la dificultad para concretar ciertas actuaciones durante la fase de diseño y, en otros, la lógica de prueba y error que conlleva un proceso experimental como Equal, son los argumentos esgrimidos a favor de la interpretación flexible que se demanda sobre los compromisos establecidos en los documentos programáticos 196 (SAE, 2009b). 


\section{CONSIDERACIONES FINALES}

En general, existe cierto consenso entre los diversos actores consultados que han participado en las iniciativas basadas en la acción de un partenariado analizadas por los autores y autoras acerca de la pertinencia y potencial del modelo basado en la cooperación institucional para alcanzar objetivos de políticas públicas de manera más integral; evidenciándose que aunque el trabajo desde la individualidad constituye la modalidad de gestión más sencilla -por su rapidez y comodidad-, la colaboración institucional presenta mayor capacidad para generar los resultados esperados.

En este sentido, la acción interinstitucional ofrece un marco flexible, en el que tienen cabida actuaciones adaptadas a cada contexto de intervención en el que se aplican y/o a los colectivos a las que están destinadas.

No obstante, el logro de los objetivos planteados pareciera estar condicionado por la operatividad del proceso de gestión; que a su vez depende de la coexistencia de ciertos factores clave, entre los que destacan:

- La puesta en marcha de mecanismos de coordinación (de los nodos de la red y de los recursos del territorio) adecuados.

- La implementación de mecanismos de asignación de tareas y responsabilidades que promuevan la interacción entre los nodos de la red y la generación de compromisos duraderos.

- La existencia de canales claros de comunicación entre los miembros del partenariado.

- La disposición de medios humanos, materiales y económicos suficientes y pertinentes.

- El planteamiento de objetivos basados en problemáticas integrales y multidimensionales.

- El consenso respecto del modelo de participación que se quiere impulsar.

- Voluntad para poner a disposición del partenariado los recursos que cada entidad posee para, a través de la acción participativa, determinar cómo se administran.

- Voluntad política de la Administración Pública para dinamizar a los actores locales y para someterse a las reglas de funcionamiento de la acción del partenariado.

La necesaria conjunción de estos elementos exige, ciertamente, la puesta en marcha de mecanismos de evaluación que permitan redireccionar las estrategias de 
intervención sobre la marcha, posibilitando allanar el terreno hacia el logro de los objetivos planteados.

Esto requiere ampliar el foco de análisis del proceso evaluador, atendiendo tanto a las estrategias operativas como a las estrategias institucionales implementadas en el marco de la gestión conjunta de las políticas públicas. Las cuestiones abordadas en este documento aspiran a aportar luz en estos aspectos concretos y a generar una red de evaluadores y evaluadoras interesados en la evaluación de partenariados y en partenariado.

\section{REFERENCIAS BIBLIOGRÁFICAS Y DOCUMENTALES}

Alburquerque, F. y Dini, M. (2008), Guía de aprendizaje sobre integración productiva y desarrollo económico territorial. Sevilla: IDR y CSIC.

Banco Mundial (2004), Seguimiento, instrumentos, métodos y enfoques. En línea: <http://www.worldbank.org/ieg/> (consulta: enero de 2010).

Borrás, S. (2009), “La Comisión Europea como intermediario en las redes de políticas públicas”, Gestión y Análisis de Políticas Públicas, Nueva Época 1: 17-42.

Bustelo Ruesta, M. (2001), La evaluación de las políticas públicas de igualdad de género de los gobiernos central y autonómicos en España: 1995-1999. Tesis Doctoral, Universidad Complutense de Madrid.

Calame, P. (2006), Tesis para repensar la gobernanza. En línea: <http://www.institutgouvernance.org/es/dossiers/motcle-dossiers-38.html> (Consulta: 8 septiembre 2009).

Chaqués Bonafont, L. (2009), “Nuevo paradigma, nuevo contexto institucional: el caso de la política farmacéutica”, Gestión y Análisis de Políticas Públicas, Nueva Época, 1: 65-86.

Chen, H. T. (2005), Practical Program Evaluation: Assessing and improving planning; implementation and effectiveness. Londres: Sage.

Comisión de las Comunidades Europeas (2001), La Gobernanza Europea. Un Libro Blanco. Bruselas: Commission of the European Comunities, COM: 428.

Davies, R. (2004), "Scale, Complexity and the Representation of Theories of Change", Evaluation, 10: 101-121.

Díez, M. A. (2007), “La evaluación basada en la teoría: una aproximación a los diferentes modelos", en Materiales pedagógicos de la Maestría Internacional de Evaluación de Políticas Públicas, UNIA. MIMEO.

Garrido, F.J. (2003), “El análisis de redes en el desarrollo local”, en T. Villasante, M. Montañés y P. Martín, coords., Prácticas locales de creatividad social. Barcelona: EI Viejo Topo.

Handicap Internacional, Grupo de Trabajo Partenariado (2002), Partenariado. Comprender nuestras colaboraciones para constituir mejor el partenariado. Manual técnico para uso interno: enfoque y herramientas para los equipos. Handicap International. Publicación digital. En línea:<http://www.handicap-international.de/fi-

198 leadmin/redaktion/pdf/partenariat_es.pdf> (Consulta: 10 febrero 2010). 
Kingdon, J. W. (1995), Agendas, alternatives and public policies. Nueva York: Harper Collins College Publishers.

Jordana, J. (2009), "Examinando las redes de actores en el análisis de las políticas públicas: debate teórico y técnicas cuantitativas", Gestión y Análisis de Políticas Públicas, Nueva Época 1: 9-16.

Kjaer, L. (2003), Local partnerships in Europe. An action research project. Copenague: The Copenhagen Centre.

Martínez García, M.F. y Martínez García, J. (2003), “Coaliciones Comunitarias: una Estrategia Participativa para el Cambio Social”, Intervención Psicosocial, 12(3): 251267.

Mataix, C. (2007), "Redes organizativas", en Materiales pedagógicos del Magíster de Evaluación de Políticas Públicas de la Universidad Complutense de Madrid. Mimeo.

Ministerio de Asuntos Exteriores y Cooperación (2007), Manual de Gestión de Evaluaciones de la Cooperación Española. Madrid: Secretaría de Estado para la Cooperación Internacional y para Iberoamérica (SECIPI).

Murciano, J. (2006), "Evaluación de partenariados y evaluación en partenariados. El caso de la Iniciativa Comunitaria Equal en Andalucía”, Revista de la Sociedad Española de Evaluación, 3: 18-31. En línea: <www.sociedadevaluacion.org> (consulta: enero 2010).

Organización Internacional del Trabajo (2008), Programa Área. Concepto de desarrollo local. En línea: <http://www.programa-area.org> (consulta: 8 septiembre 2009).

Osuna, J.L., Vélez, C., Cirera, A. y Murciano, J. (2006), "Programación y Evaluación Pública: un triángulo complejo”, Ekonomiaz. Revista Vasca de Economía, 60: 76-97.

Román, C. y Rodríguez, P., coords. (2004), La contribución del capital social a la creación de empleo en Andalucía. Sevilla: Instituto de Desarrollo Regional.

Román, C. (2001), Aprendiendo a innovar. El papel del capital social. Sevilla: Instituto de Desarrollo Regional.

Servicio Andaluz de Empleo (SAE) (2007), Guía de presentación de proyectos acogidos a la segunda convocatoria de la Iniciativa Comunitaria Equal en Andalucía 20042007. Sevilla: Servicio Andaluz de Empleo. Consejería de Empleo. En línea: <www. juntadeandalucia.es/empleo/equal> (Consulta: 11 febrero 2010).

Servicio Andaluz de Empleo (SAE) (2009a), Redes de cooperación institucional. Evaluación de la experiencia Equal en Andalucía. Sevilla: Servicio Andaluz de Empleo. Consejería de Empleo. Junta de Andalucía. Elabora: Instituto de Estudios de Economía, Evaluación y Empleo. En línea: <www.juntadeandalucia.es/empleo/ equal> (Consulta: 11 febrero 2010).

Servicio Andaluz de Empleo (SAE) (2009b), Informe de Evaluación final de impactos. Iniciativa Comunitaria Equal en Andalucía. Resumen ejecutivo. Sevilla. Edita: Servicio Andaluz de Empleo, Consejería de Empleo, Junta de Andalucía. Elabora: Instituto de Estudios de Economía, Evaluación y Empleo. En línea: <www.juntadeandalucia.es/empleo/equal> (Consulta: 11 febrero 2010).

Savas, E. S. (2000), Privatization and public-private partnerships. Nueva York: Chatham House Publishers.

Stake, R. (2006), Evaluación comprensiva y evaluación basada en estándares. Barcelona: Editorial Graó. 
Subirats, J. (2005), “Catorce puntos esenciales sobre evaluación de políticas públicas con especial referencia al caso de las políticas sociales", Ekonomiaz, Revista Vasca de Economía, 60(1): 18-37.

Vélez, C. (2006), “La evaluación: un nuevo yacimiento de empleo”, E-valuación. Revista de la Sociedad Española de Evaluación, 3: 4-17.

Vélez, C. (2007), “El cambio de paradigma en evaluación de políticas públicas: el caso de la cooperación al desarrollo”, en M.J. Terol Becerra, dir., Nuevas políticas públicas. Anuario Multidisciplinar para la modernización de las Administraciones Públicas. Sevilla: Instituto Andaluz de Administración Pública.

Weiss, C. (1998), Evaluation. Upper Saddle River, Prentice Hall.

Recibido: 1 de marzo de 2010

Aceptado: 28 de abril de 2010 